\title{
Drop Tests of the Closure Ring for the 9975 Package
}

by

A. C Smith

Westinghouse Savannah River Company

Savannah River Site

Aiken, South Carolina 29808

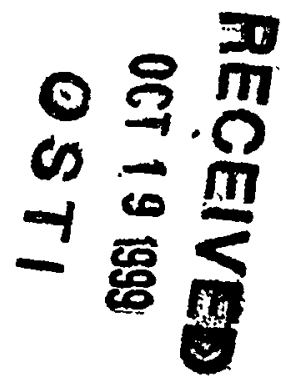

DOE Contract No. DE-AC09-96SR18500

This paper was prepared in connection with work done under the above contract number with the U.S. Department of Energy. By acceptance of this paper, the publisher and/or recipient acknowledges the U.S. Government's right to retain a nonexclusive, royalty-free license in and to any copyright covering this paper, along with the right to reproduce and to authorize others to reproduce all or part of the copyrighted paper. 


\section{DISCLAIMER}

This report was prepared as an account of work sponsored by an agency of the United States Government. Neither the United. States Government nor any agency thereof, nor any of their employees, makes any warranty, express or implied, or assurnes any legal liability or responsibility for the accuracy, completeness, or usefulness of any information, apparatus, product, or process disclosed, or represents that its use would not infringe privately owned rights. Reference herein to any specific commercial product, process, or service by trade name, trademark, manufacturer, or otherwise does not necessarily constitute or imply its endorsement, recommendation, or favoring by the United States Government or any agency thereof. The views and opinions of authors expressed herein do not necessarily state or reflect those of the United States Government or any agency thereof.

This report has been reproduced directly from the best available copy.

Available to DOE and DOE contractors from the Office of Scientific and Technical Information, P.O. Box 62, Oak Ridge, TN 37831; prices available from (615) 576-8401.

Available to the public from the National Technical Information Service, U.S. Department of Commerce, 5285 Port Royal Road, Springfield, VA 22161. 


\section{DISCLAIMER}

Portions of this document may be illegible in electronic image products. Images are produced from the best available original document. 


\section{WESTINGHOUSE SAVANNAH RIVER COMPANY \\ INTEROFFICE MEMORANDUM}
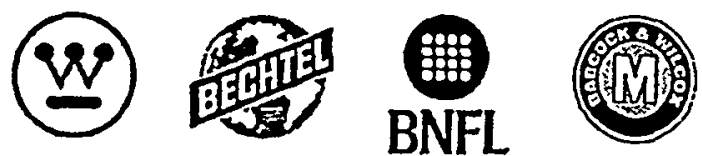

SRT-PTG-99-0029

July 30, 1999

To: S.M. King, 773-54A

Cc: M. Ebra, 773-42A

T. Bolt, (P\&TG File), 773-54A

P. Woodward, File 22628, 730-A

From:

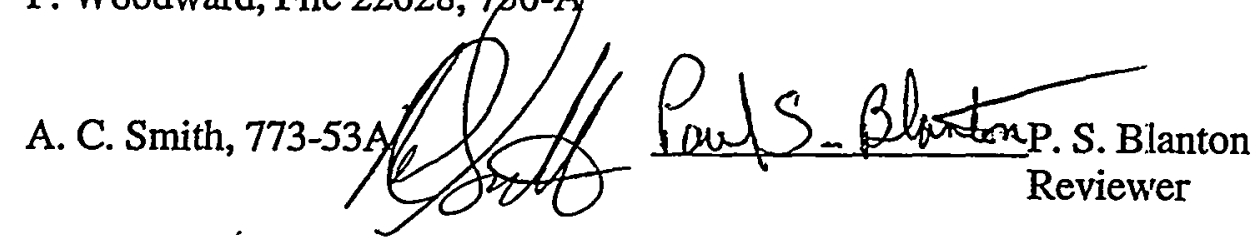

\section{DROP TESTS OF THE CLOSURE RING FOR THE 9975 PACKAGE(U)}

Reference: Tests of 9975 Packages with Pressurized Containment Vessels, A.C. Smith, SRT-PTG-980116, September 22, 1998

Post test review of damage to the drum closure assembly of the 9975 package tested in September of 1998 identified a possible vulnerability to a subsequent pin drop. It was hypothesized that a pin strike on the closure ring could remove the ring and result in loss of the top of the drum. This would, in turn, expose the Celotex overpack material to a subsequent fire.

The purpose of the testing described here was to resolve the question of this possible vulnerability. The initial phase consisted of 30 foot drop tests to envelop the damage condition identified in the earlier tests. Following consultation with the regulatory review agency (LLNL) the package judged to be most vulnerable to a pin drop was identified and subjected to a one meter drop onto the pin. The package was oriented so that the pin would strike the closure ring in such a way as to dislodge it from the package.

The test achieved the intended pin strike, resulting in the closure ring being pushed over the rolled rim of the drum in the vicinity of the point of impact. However, the closure ring remained in position and the top remained securely attached to the drum. Consequently, the ability of the package to withstand a subsequent HAC fire event would not be compromised. 
Keywords:

9975 Shipping Package

Drop Test

\title{
Drop Testing of Closure Ring \\ for \\ 9975 Packages
}

\author{
A.C. Smith \\ May, 1999
}

\section{Patent Status}

This internal management report is being transmitted without DOE patent clearance and no further dissemination of publication shall be made without prior approval of the DOE patent counsel.

SAVANNAH RIVER TECHNOLOGY CENTER, AIKEN, SC 29808

Westinghouse Savannah River Co.

Prepared for the U.S. Department of Energy under Contract DE-AC09-96SE18500 
Table of Contents

Summary.......................................................................... 1

1.0 Background..................................................................... 1

2.0 Test Program.............................................................. 2

3.0 Test Apparatus............................................................... 2

4.0 Drop Tests..................................................................... 3

5.0 Testing and Results...................................................... 4

6.0 Discussion.................................................................. 6

7.0 Conclusions.................................................................... 7

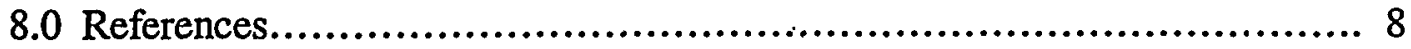
Figures 


\section{List of Figures}

Figure 1. Package 0247 rigged in the $10^{\circ}$ top down attitude, using two slings. The package rotated slightly during the drop and struck on its bottom chine, in a $10^{\circ}$ bottom down attitude. This satisfied the objective of the slap-down case.

Figure 2. Deformation at the top closure of 0247 following the 30 foot drop. The ridge or crease marking the top of the Celotex pack appears as bright line of reflection paralleling the closure ring. The closure ring is seen to be in close contact with the drum all along the deformed region. The rolled rim of the drum is essentially straight across the flattened region.

Figure 3. End view of 0247, showing the flattened closure ring and buckled edge of the top.

Figure 4. The height of the Celotex pack was corrected by addition of two $1 / 2$ in. thick disks to the bottom of the Celotex pack. The drum was inverted and lifted off of the Celotex pack assembly. The disks, which were of slightly smaller diameter, were then attached to the bottom of the assembly.

Figure 5. The test drum rigged for a $10^{\circ}$ top down drop, using a single sling. The single sling and other procedural changes enable achieving consistent drops at close to the desired angle at impact.

Figure 6. Package 0246 rigged for the $10^{\circ}$ top down drop. Actual impact was at $8.1^{\circ}$.

Figure 7. View of inner side of damaged region of top on package 0246.

Figure 8. View along the plane of the flattened region of package 0246. The closure ring is seen to be close to the drum surface at all locations, and is engaged with the rolled rim of the drum. The rolled rim of the drum is essentially straight across the flattened region. The ridge formed at the top of the air shield/Celotex pack assembly is immediately below the lower edge of the closure ring.

Figure 9. Package 0141 rigged for the $15^{\circ}$ top down drop. The actual impact was at $14^{\circ}$.

Figure 10. View of inner side of damaged region of top of package 0141. The higher angle at impact resulted in more damage in the region of initial impact. More extensive buckling of the top is apparent in this view.

Figure 11. View of the inner surface of the damaged region of the top of 0141.

Figure 12. The damage for the $14^{\circ}$ impact displays characteristics similar to that observed in higher angle corner drops. The most significant damage is confined to the trapezoidal flattened region. Buckling of the transition regions between the curved sides and the flattened area is more pronounced and there is more extensive buckling of the top than in the lower angle impact cases. 
Figure 13. View along the plane of the flattened region of package 0141. Although the deformation is greater than in the previous cases, the closure ring is seen to be close to the drum surface at all locations, and is engaged with the rolled rim of the drum. The ridge formed at the top of the air shield/Celotex pack assembly is immediately below the lower edge of the closure ring. The closure ring " $\mathrm{C}$ " section is flattened at the transition between the damage region and the curved, undamaged region.

Figure 14. Package 0141 rigged in position for the pin drop test. The target was the closure ring at the transition from the flattened region to the curved, undamaged region.

Figure 15. Package 0142 in the raised position in preparation for the pin drop test. The plumb bob confirms the target alignment.

Figure 16. Package 0141 following the pin impact on the bottom of the closure ring. The impact is seen to have forced the ring over the rolled rim of the drum.

Figure 17. The impact marking on the top of the painted surface of the pin confirms that the closure ring struck the pin squarely.

Figure 18. Close-up view of the target area. The view shows that the closure ring struck the pin at its most vulnerable location, at the point of transition between the flattened side and the curved, undamaged region. The ring was pushed just over the rolled rim of the drum. The rolled rim of the drum, visible here, is seen to be almost straight in the flattened region, not following the reverse curvature shown by the edge of the top in the top views.

Figure 19. View from inner side of the damaged region of the top, showing the buckling of the edge and disk of the top and the inner surface of the closure ring in its displaced position.

Figure 20. Close-up of the pin impact point on the closure ring. As indicated by the mark on the ring, the pin struck the bottom edge of the ring at the transition between the flattened side and the undamaged curved region. The flattened section of the rolled rim of the drum is clearly show in this view. The parallel ridge marking the top of the air shield-Celotex pack assembly is seen close to the rolled rim.

Figure 21. Overall view of the damage region of package 0141.

Figure 22. Overall view of the damage region of the top of package 0141. 


\section{Drop Testing of the Closure Ring Configuration for 9975}

\section{Summary}

The drop tests of the closure ring for 9975 packages, described here, were performed to answer questions raised by the regulatory authority as a result of deformation of the closure ring and drum rim observed during drop tests conducted in September 1998 (Reference 1).

In planning for the test it was recognized that the gasket supplied for the top of the drum was a thick foam rubber gasket, whereas that used on the prototype certification test units was a thinner neoprene gasket (References $2 \& 3$ ). It was recognized that the thinner gasket allowed closer fit-up of the top, or lid, and drum rim and that this could affect the response of the closure to impact. The foam rubber gasket was replaced with the neoprene gasket for all tests conducted in this test series.

Following the first test, it was recognized that the design, as certified, allowed a one inch gap between the top of the air shield and the bottom of the drum lid. It was postulated that this gap allowed greater deformation of the drum closure assembly compared to the configuration of the prototype certification test units, where this region of the drum was backed-up by the celotex interior pack. For the second and third tests, this gap was closed by attaching two celotex disks to the bottom of the celotex pack.

The results showed that in each case the closure ring remained close to the drum. Accordingly, the gap between the closure ring and the rolled rim of the drum, observed in the September tests, was not present: Consequently; the concern expressed (with respect to the September test) that the ring would be vulnerable to a pin striking an unsupported section of the closure ring was resolved.

Upon review of the test results, the regulatory review agency, Lawrence Livermore National Laboratory, requested an additional test. The test requested was a pin drop with the package oriented so that the pin impact would be on the bottom of the package closure ring, striking the ring at the transition from the flattened region to the undamaged curved region of the ring. This test was subsequently performed and the results showed that the top, or lid, remained securely attached to the drum following this additional test.

\subsection{Background}

\section{Background}

In the course of drop testing performed to qualify a higher MNOP for the 9975 containment vessels, deformation of the top rim-closure ring region of one package was greater than expected. The package rotated slightly during drop and struck at angle of about $10^{\circ}$, with the initial strike on the top rim. The resulting deformation of the top rolled rim resulted in a gap between the rolled rim and the closure ring . in the central part of the damage region (Reference 1). The package subsequently successfully retained its top even though it was subjected to two additional 30-foot drops. The cleformation was sufficient to raise the question of the ability of the closure ring to remain in place in a pin drop test. In particular, the ring was considered potentially vulnerable if it were struck in the area where the gap existed between the ring and the rolled rim of the drum. 
The second package dropped in the September series did not rotate detectably, striking in a horizontal attitude, and did not display as much deformation at the top rim as the first drop. In particular, there was no gap between the closure ring and the rolled rim in the damage region.

A test program was developed to respond to the concerns expressed by the regulatory authority. The essential elements of the test program were:

1. Duplicate conditions of first drop of the September 1998 tests.

2. Determine if the resulting damage would be vulnerable to pin inpact.

This plan was modified in light of lessons learned while developing the test program and during the test program.

Following discussion of the drop tests results with the regulatory review agency, a pin drop test was performed. For the pin drop test, the package was arranged so that the pin impact would be on the bottom of the closure ring, at the transition between the flattened side and the undamaged curved region of the closure ring.

\subsection{Test Program}

The proposed test program consisted of three tests at angles of impact which would envelope the $10^{\circ}$ orientation of the suspect package from the September series. This test program consisted of nominal angles of impact of $10^{\circ}$ and $14^{\circ}$, and a slap-down test. In the slap-down test, the bottom chine would strike first, at a $10^{\circ}$ angle, with subsequent slap-down of the drum.

The pin drop test was performed on the package that experienced the $14^{\circ}$ impact. The package was oriented so that the pin struck the bottom of the closure ring at the transition between the flattened region of the closure ring and the undamaged curved region of the ring.

\subsection{Test Apparatus}

The test specimens were standard 9975 packages, as delivered under the current AMPCO contract (SRS Purchase Order AB97708A). The packages were loaded with dummy weights to meet their maximum allowable contents weight. The gross weight of the packages, ready for testing was between 426 and $431 \mathrm{lb}$., somewhat over the $404 \mathrm{lb}$. given in the SARP. For purposes of drop testing the greater weight represents a more severe test condition. Specifically, these results are applicable to packages at the 404 $\mathrm{lb}$. listed in the Certificate of Compliance.

The packages were planned to be identical to those tested in the September test series. However, in pretest discussions it was recognized that the top gasket for the drum was different than for tests conducted in the past of related packages, such as the 9968. The packages in the current production run have a thick foam rubber gasket, which results in greater separation of the top and drum rim when assembled. This was the configuration employed in the September testing. Earlier 9968-9975 series package testing, on which the SARP is based, employed a thinner, neoprene gasket. It was recognized that the difference in gasket could have contributed to the package closure response. Consequently the gasket was replaced with a thin neoprene gasket for the present series of tests. 
The packages were assembled according to standard procedure, except for leak testing. Since the object of this series of tests was to investigate the response of the closure ring assembly under shallow angle impact, the containment vessels were included only for weight and completeness of package geometry, and were not leak-tested as part of the test procedure.

The examination of the package following the first 30 foot drop test, which was the slap-down, revealed that there was a noticeable crease at the location corresponding to the top of the air shield on the celotex pack. It was recognized that there was a gap between the air shield and the top of the drum. In the absence of the celotex for back-up, this region was free to deform more extensively that if the celotex was present. It was also recognized that the intent of the design was that the celotex pack should fill the drum, so that no such gap would be present. Following the first test, this heat-shield-to-top gap was corrected by addition of celotex disks to the bottom of the celotex pack, for the subsequent two tests.

\subsection{Drop Tests}

The 30 foot drop tests were performed in the 723-A high bay drop test facility in accordance with Field Procedure FP-806, "Drop Tests of the 9975 series Shipping Package", Reference 6. For each drop, the package was aligned to within $1^{\circ}$ of its nominal orientation prior to the drop. Following each drop, the package was measured and photographed to document the extent of damage. The orientation at impact was determined from the high speed video of the test.

The drop test surface was constructed from a 6.25 inch thick armor plate, approximately 5 feet square, anchored in a 30 inch thick reinforced concrete slab. The target slab is isolated from the concrete floor of the building. The target slab weighs approximately $15,600 \mathrm{lb}$., which is over 35 times the maximum weight of the test packages (431 lb.).

The pin drop tests employed a 40 inch tall, $15 \mathrm{~cm}$ diameter pin welded in place on the drop pad. The specimen package requested by the regulatory review agency was subjected to the drop. The package was rigged for impact on the transition between the flattened section and the curved, undamaged section of the closure ring. In keeping with the regulatory requirement of a pin drop, the package was dropped from a height of one meter above the top of the pin.

\subsection{Testing and Results}

\section{First Test Drop (FP-806-9975-HD-1, package serial number 0247)}

The first test was the slap-down case, striking bottom first with the axis inclined at $10^{\circ}$ from the horizontal. The damage followed a pattern somewhat like that of the September test, but the closure ring remained close to the side of the drum and in intimate contact with drum rim (Figures 1,2 and 3). As a result, the closure ring would not be vulnerable to a pin strike. Buckling of the inverted "I"shaped rim of the top, or lid, was significantly less than in the September tests. 
Post Drop Dimensions:

Diameter to mid point of damaged area: $173 / 8$ in.

Diameter parallel to flattened area: $185 / 8$ in.

Width of flattened area: 10 in.

Inside of buckle to outside of ring: $11 / 2$ in.

Undamaged height: 36 in.

Maximum height at damaged area: $363 / 8$ in.

Changes in test arrangements

The post drop examination revealed a crease, which could be felt, at a position corresponding to top edge of air shield. This indicated that the air shield was not as high as intended in the design concept. (although, it did conform to the current production drawings). It was recognized that the deformation was greater at the closure ring-rim region because of the absence of supporting celotex material backing up the drum in this region. The crease indicated that the side of the drum tended to rotate about the edge of the air shield as it crushed inward.

To correct the deviation from the intended configuration, the celotex packing was raised (by the addition of celotex disks at the bottom of the pack) for the remaining tests (Figure 4). The modified packing height minimized the gap between the top of the air shield and the drum lid, and conformed to the 9968 configuration which was the basis for the overpack design.

\section{Second Test Drop (FP-806-9975-HD-2, package serial number 0246)}

Package 0246, incorporating the thin neoprene gasket and additional celotex disks was dropped with the objective of duplicating the September drop orientation. Accordingly, the package was rigged in a $10^{\circ}$ (from horizontal), top down orientation (Figure 6). The drop achieved the intended orientation, resulting in an impact at $8.1^{\circ}$ from horizontal, with the top striking first.

The damage to the drum was similar in general character to the preceding horizontal drop tests. However, the closure ring was in intimate contact with drum rim throughout the damaged region (Figures 7 and 8). The transition from flattening of the side to crushing at rim observed in first drop (resulting in the ridge or crease at the top of the air shield) was not apparent. The side of the drum was clearly well supported up to near the bottom edge of the ring. Buckling of the curved rim of the top was less than that seen in the September test.

Post Drop Dimensions:

Diameter to mid point of damaged area: $173 / 16 \mathrm{in}$.

Diameter parallel to flattened area: $185 / 8$ in.

Width of flattened area at rolling rings: 9 in.

Inside of buckle to outside of ring: $15 / 8$ in.

Undamaged height: 36 in.

Maximum height at damaged area: $363 / 8$ in. 


\section{Third Test Drop (FP-806-9975-HD-3, package serial number 0141)}

Package 0141 also incorporated the thin neoprene gasket and additional celotex disks. It was rigged for a $15^{\circ}$ (from horizontal), top down orientation at impact (Figure 9). The drop achieved the intended orientation, resulting in an impact at $14^{\circ}$ from horizontal, with the top striking first.

The damage was more localized in the region of initial impact than in the earlier tests in this series. In addition, it displayed characteristics similar to those in other moderate-angle corner impact tests. The boundary of the damage region displayed additional buckling of the drum wall paralleling the initial impact area (Figures 10,11,12 and 13). The closure ring remained in intimate contact with drum throughout the damaged region. In spite of the more localized damage, the side of drum was clearly well supported up to near the bottom edge of the closure ring. Buckling of the curved rim of the top was less than that seen in the September test.

\section{Post Drop Dimensions:}

Diameter to mid point of damaged area: $1615 / 16 \mathrm{in}$.

Diameter parallel to flattened area: $183 / 4$ in.

Width of flattened area at rolling rings: 8 in.

Inside of buckle to outside of ring: $19 / 16$ in.

Undamaged height: 36 in.

Maximum height at damaged area: $363 / 8$ in.

\section{Pin Drop (FP-806-9975-HD-3, Pin Drop, package serial number 0141)}

Package 0141 (the package requested by the regulatory review agency, LLNV) was rigged for impact on the transition between the flattened section and the curved, undamaged section of the closure ring (Figures 14 and 15). The package was oriented $10^{\circ}$ from vertical with the target location above the edge of the pin. The package struck the pin at the intended location (Figures 16 through 22).

The results showed the closure ring displaced in the region of the target point. For an observer facing the package, this region extended for an arc of about $5^{\circ}$ on the right (curved side) of the target point and along the flattened region, on the left (Figure 18). Because closure ring remained engaged around most of its circumference, the top remained securely attached to the package. As seen on the high-speed video, as the drum moves past the pin the ring is pulled away enough to slide past the rolled rim of the drum.

\subsection{Discussion}

The deformation of the first package dropped in the September 1998 test series resulted in the closure ring separating from the rolled rim of the drum over a length of several inches centered about the mid point of the damage area. (Figure 3 of Reference 1). The local damage at the top of the drum was sufficient that the drum rim and closure ring were pushed inward to a greater degree than the adjacent region of the drum wall. (Figure 4 of Reference 1). Concern was expressed that a pin strike on the ring in this region could cause it to be pulled from the drum, allowing the package top, or lid, to be lost. 
In each of the cases tested in the present test, the closure ring remained engaged with the rolled rim of the drum. The first test, which was a slap-down, resulted in less deformation than the direct impact experienced in the September test and the closure ring remained close to the drum wall, and in intimate contact with the drum rim. Post test examination showed the ridge or crease corresponding to the top of the air shield an inch below the closure ring. This focused attention on the space which existed between the top of the air shield - celotex packing assembly and the bottom of the drum top, or lid. This difference between the test specimen and the design concept was recognized as a condition that could permit excessive deformation at the top of the drum, compared to earlier $9965-9975$ series package tests. For the subsequent tests, this condition was corrected by attaching celotex disks to the bottom of the celotex packing assembly.

The results of the subsequent drops confirmed this explanation. In each case, the drum wall deformation was less and the inward curve of the wall was immediately below the closure ring, so that the lower edge of the ring was not vulnerable to a pin impact event.

The $8^{\circ}$ drop very closely duplicated the first of the September 1998 drops. The results differ in the location of the ridge or crease marking the top of the air shield and the associated deformation of the top of the drum in the vicinity of the point of impact. The total deformation is less and the crease is immediately below the closure ring, so that the ring is within the envelope of the drum wall (Figure 8). Most importantly, the closure ring remains mechanically engaged with the rolled rim of the drum along all of the flattened impact area.

The $14^{\circ}$ drop displayed damage features similar to other, earlier corner drop test results. At the top of the drum, however, the flattening of the top rimi/closure assembly was much like that exhibited by the previous $8^{\circ}$ drop. As in the $8^{\circ}$ case, the crease marking the top of the air shield was immediately below the closure ring and the ring is within the envelope of the drum wall. As in the $8^{\circ}$ case, the closure ring remained mechanically engaged with the rolled rim of the drum along all of the flattened area (Figure 12).

The pin drop test resulted in the pin striking the transition between the flattened region and the undamaged, curved section of the closure ring (Figure 18). At this location, the ring has the worst combination of exposure to being hit and least engagement with the rolled rim of the drum. As noted above, the high-speed video shows that, as the drum moves past the pin, the ring is pulled away enough to slide past the rolled rim of the drum. This behavior was not observed in the practice drops, which employed a lighter drum/package assembly. For the practice drops, the ring was pulled away, but the drum was also deflected, so that the closure ring was not pulled above the rolled rim.

Following the test, a small force was applied to the closure ring in the displaced region. No indication of flexure or motion was detected. The force applied, centered around the point of impact, was progressively increased until sufficient force was applied to tip the drum ( $215 \mathrm{lb}$., vertically oriented). No flexure or indication of motion was detected as a result. The closure is clearly in a structurally stable position. Significant energy input would be required to either pull the ring from the drum, or to return it to its position below the rolled rim. The amount of effort required to further remove the ring was judged to be considerably greater that that required to return it to a position below the rolled rim. 


\subsection{Conclusion}

With the air shield - Celotex packing assembly raised to minimize any gap between the air shield and the top of the drum, the deformation observed in the September test does not occur. In particular, the closure ring remains mechanically engaged with the rolled rim of the drum. In addition, the inward deformation at the top of the drum is minimized and its location is immediately below the edge of the closure ring, so that the ring is not vulnerable to a pin strike.

The pin strike on the most vulnerable location resulted in local displacement of the closure ring. However, the drum lid remained securely attached in place. The closure ring remained under significant tension and continued to retain the top. With the top remaining securely in place, the ability of the package to withstand a fire, the next event in the $\mathrm{HAC}$ accident sequence, would not be compromised.

It is concluded that the top closure arrangement of the package is shown to meet the functional requirements for the package.

\subsection{References}

1. 'Smith, A.C., Drop Tests of 9975 Packages with Pressurized Containment Vessels, SRT-PTG-980116, September 22, 1998

2. Safety Analysis Report - Packages, $9965,9968,9972$ - 9975 Packages, WSRC-SA-7, Rev. 5, February 1998.

3. Military Specification, MS-27683-91 (Conforming to SAE-AMS-R-6855. Class 2, Grade 60), Neoprene Gasket.

4. Loading and Post Test Procedure for the Closure Ring Tests of the 9975 Shipping Container, FP-804, Rev. 0, April 12, 1999.

5. Procedure for the Final Assembly of the 9975 Shipping Container, FP-805, Rev. 0, April 12, 1999.

6. Drop Tests of the 9975 Series Shipping Package, FP-806, Rev. 0, April 12, 1999. 


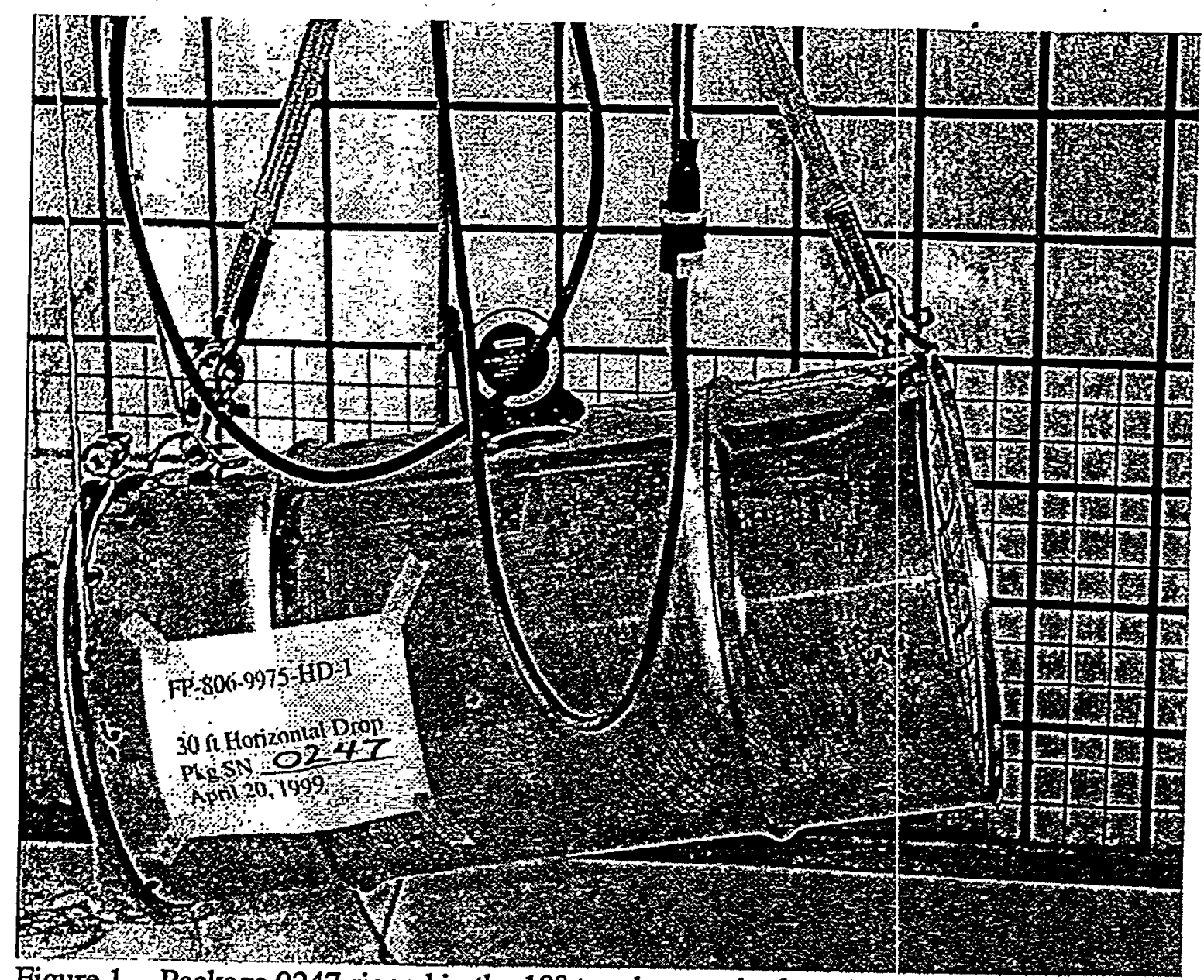

Figure 1. Package 0247 rigged in the $10^{\circ}$ top down attitude; using two slings. The package rotated slightly during the drop and struck on its. bottom chine, in a $10^{\circ}$ bottom down attitude. This satisfied the objective of the slap-down case. 


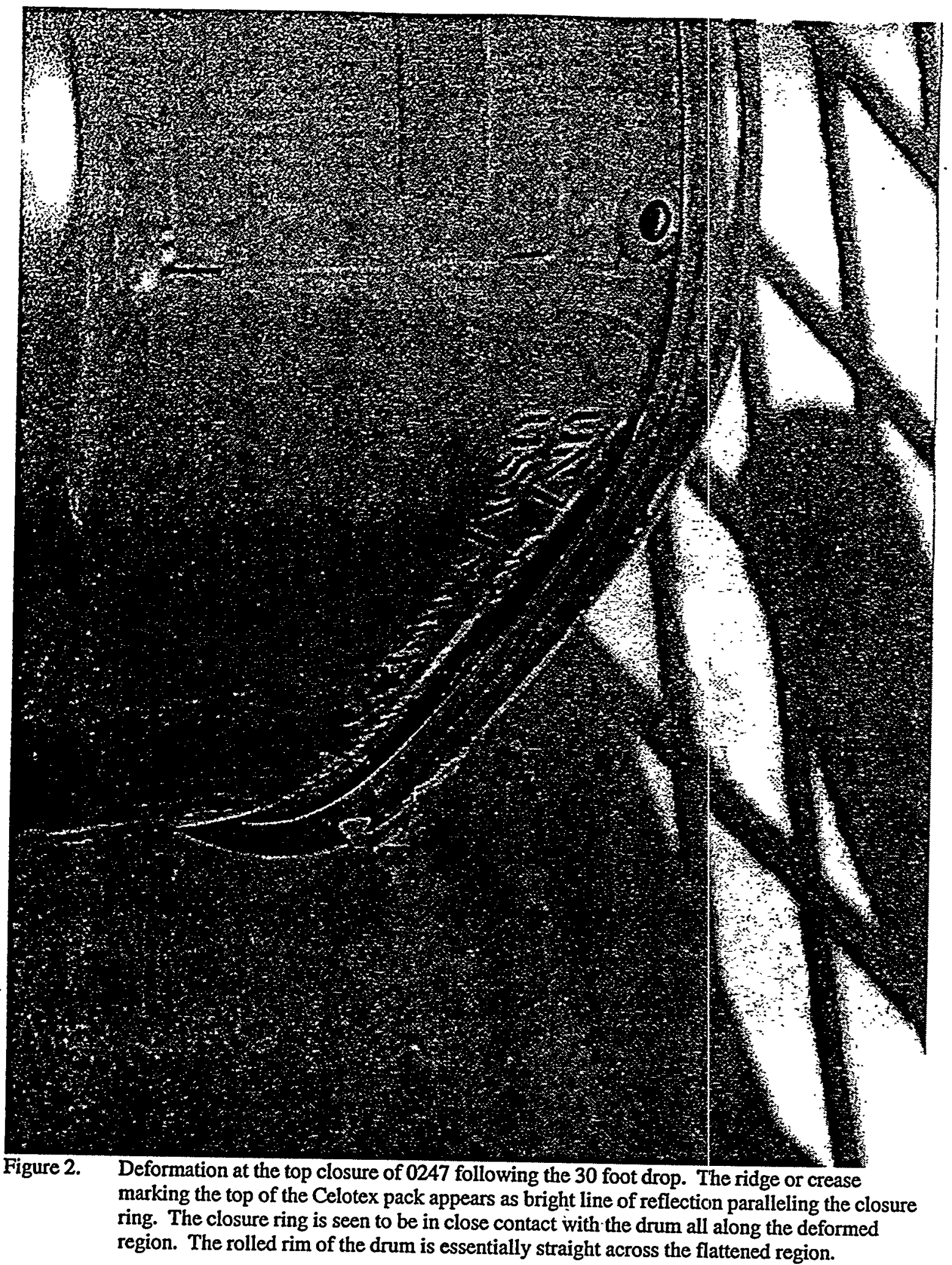




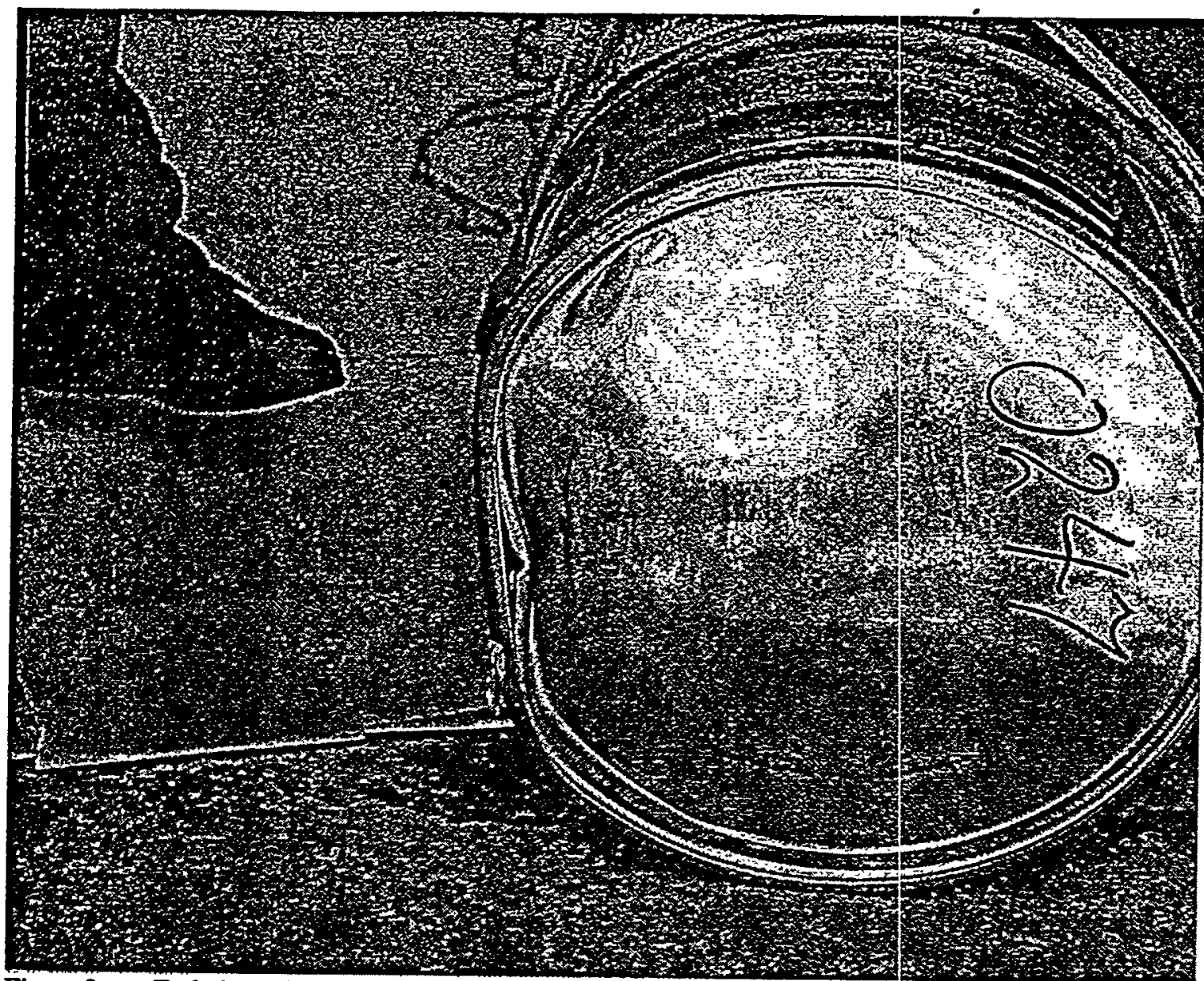

Figure 3. End view of 0247 , showing the flattened closure ring and buckled edge of the top. 


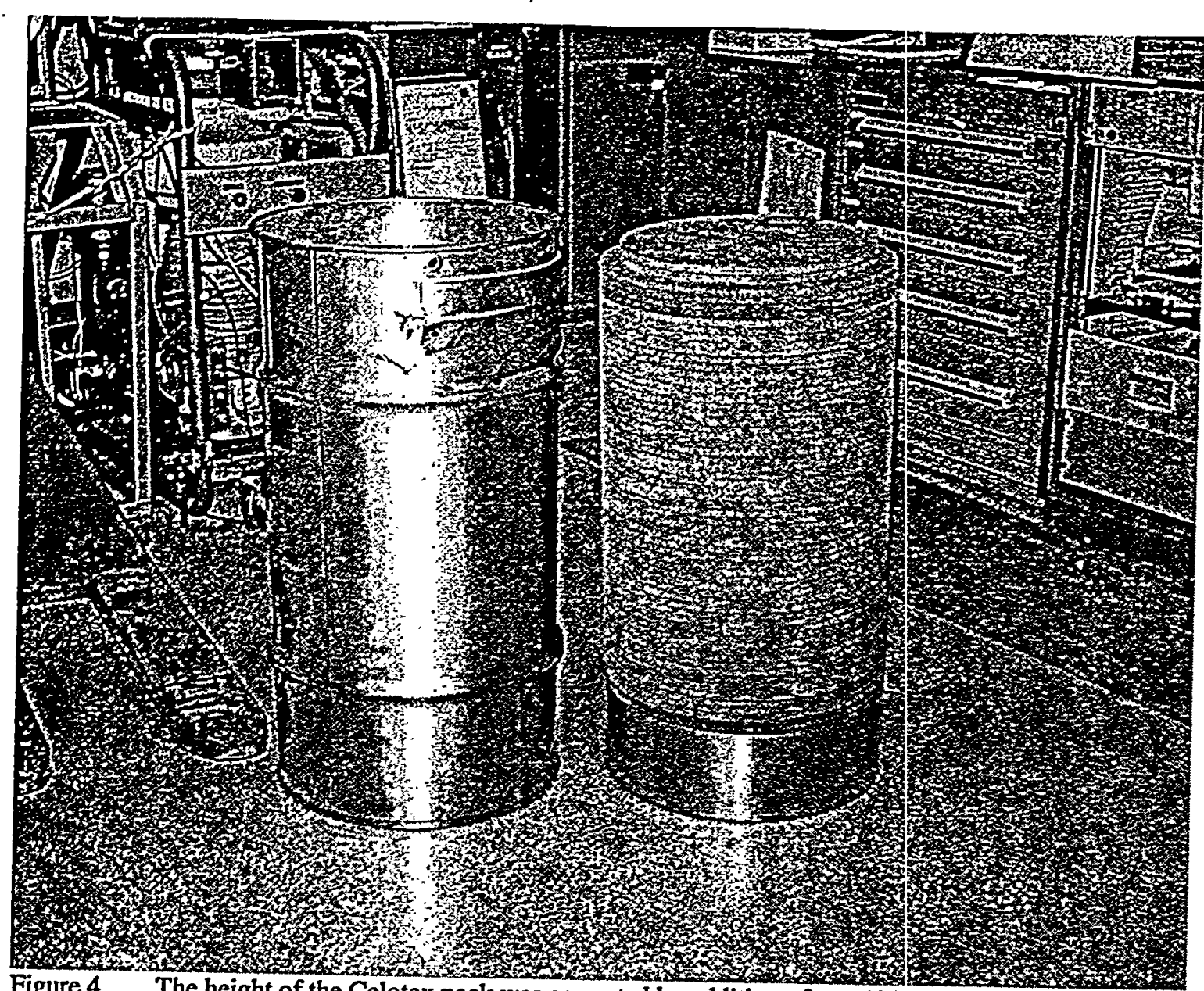

Figure 4. The height of the Celotex pack was corrected by addition of two $1 / 2$ in. thick disks to the bottom of the Celotex pack. The drum was inverted and lifted off of the Celotex pack assembly. The disks, which were of slightly smaller diameter, were then attached to the bottom of the assembly. 


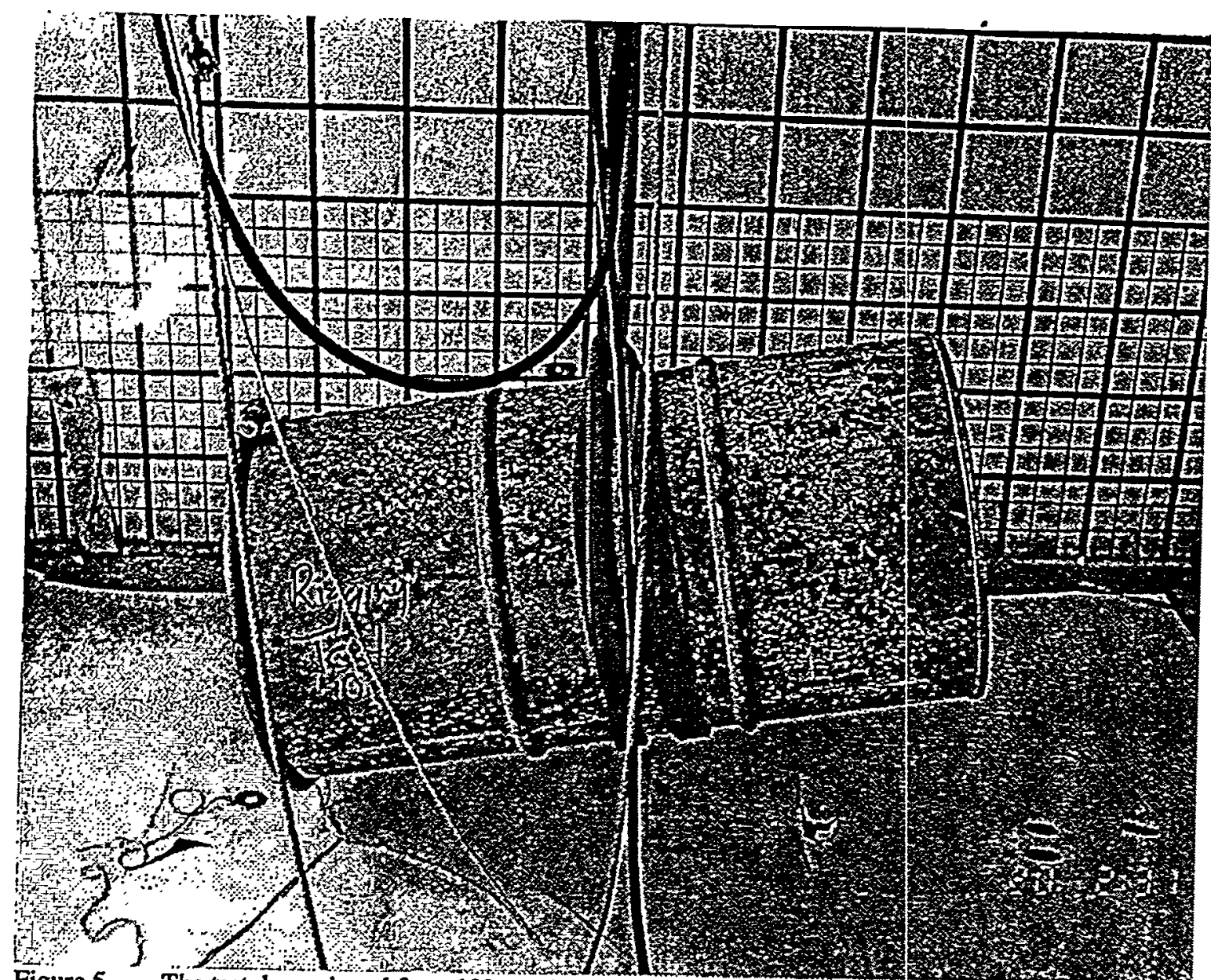

Figure 5.

The test drum rigged for a $10^{\circ}$ top down drop, using a single sling. The single sling and other procedural changes enable achieving consistent drops at close to the desired angle at impact. 


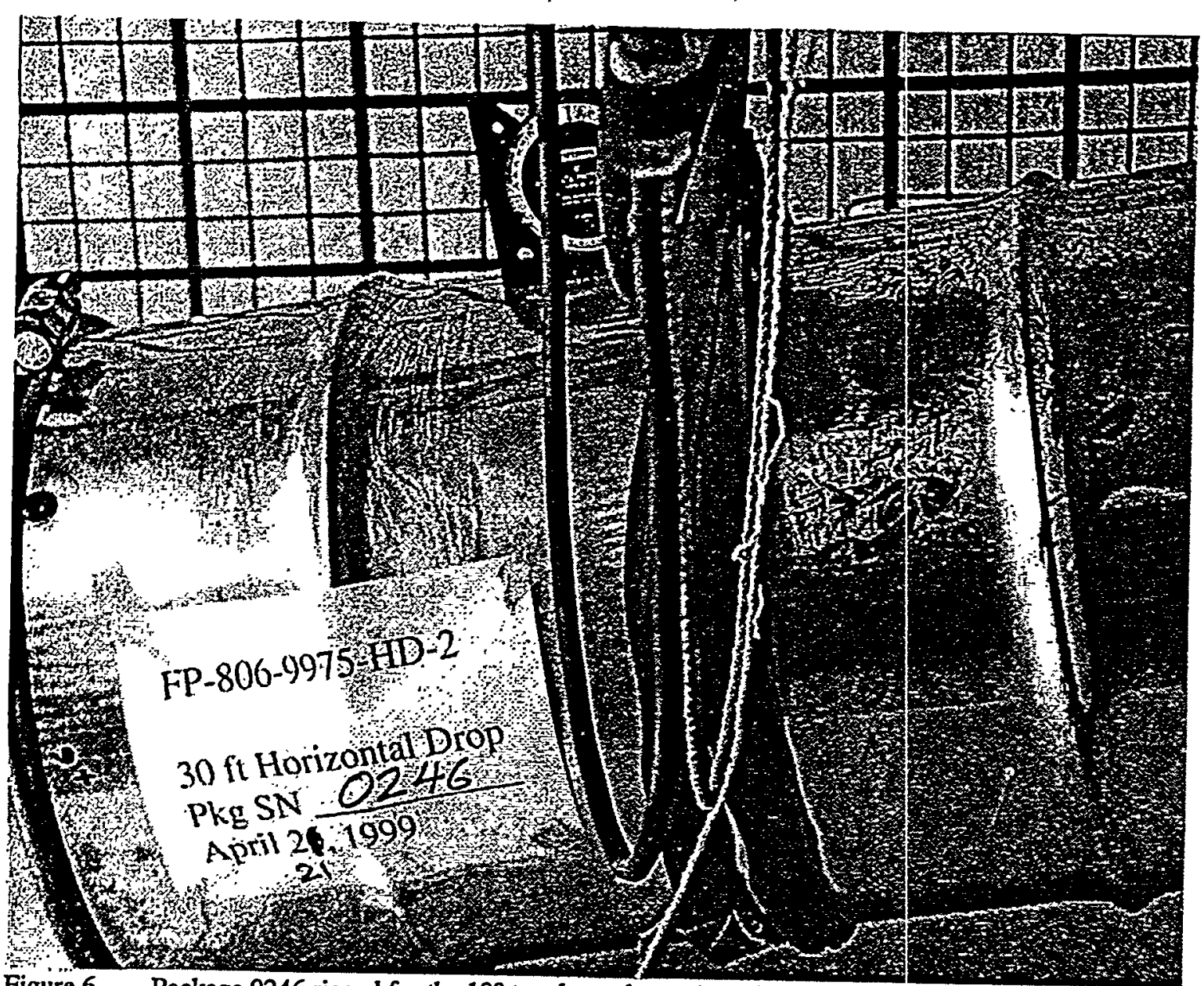

Figure 6. Package 0246 rigged for the $10^{\circ}$ top down drop. Actual impact was at $8.1^{\circ}$. 


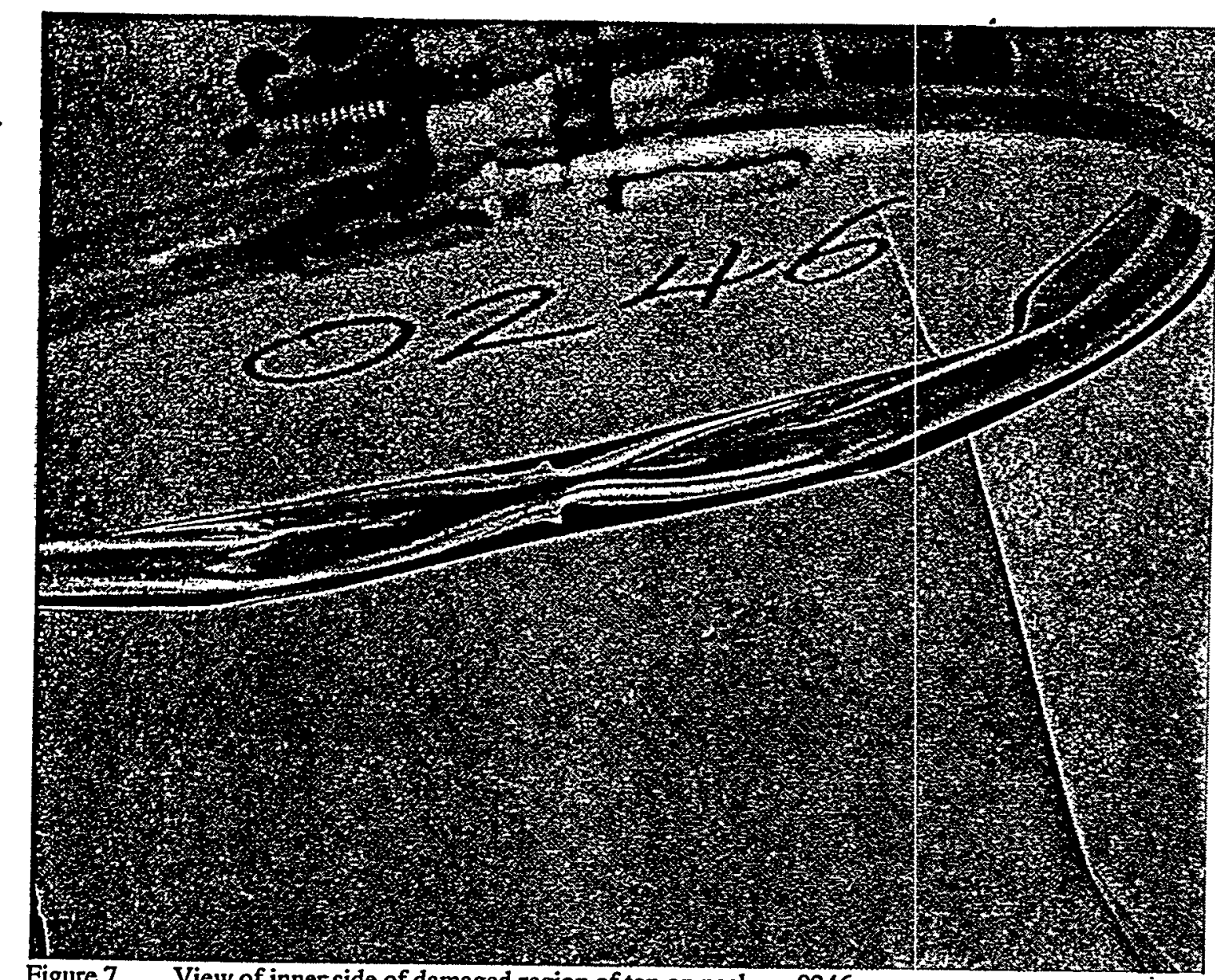

Figure 7. View of inner side of damaged region of top on package 0246. 


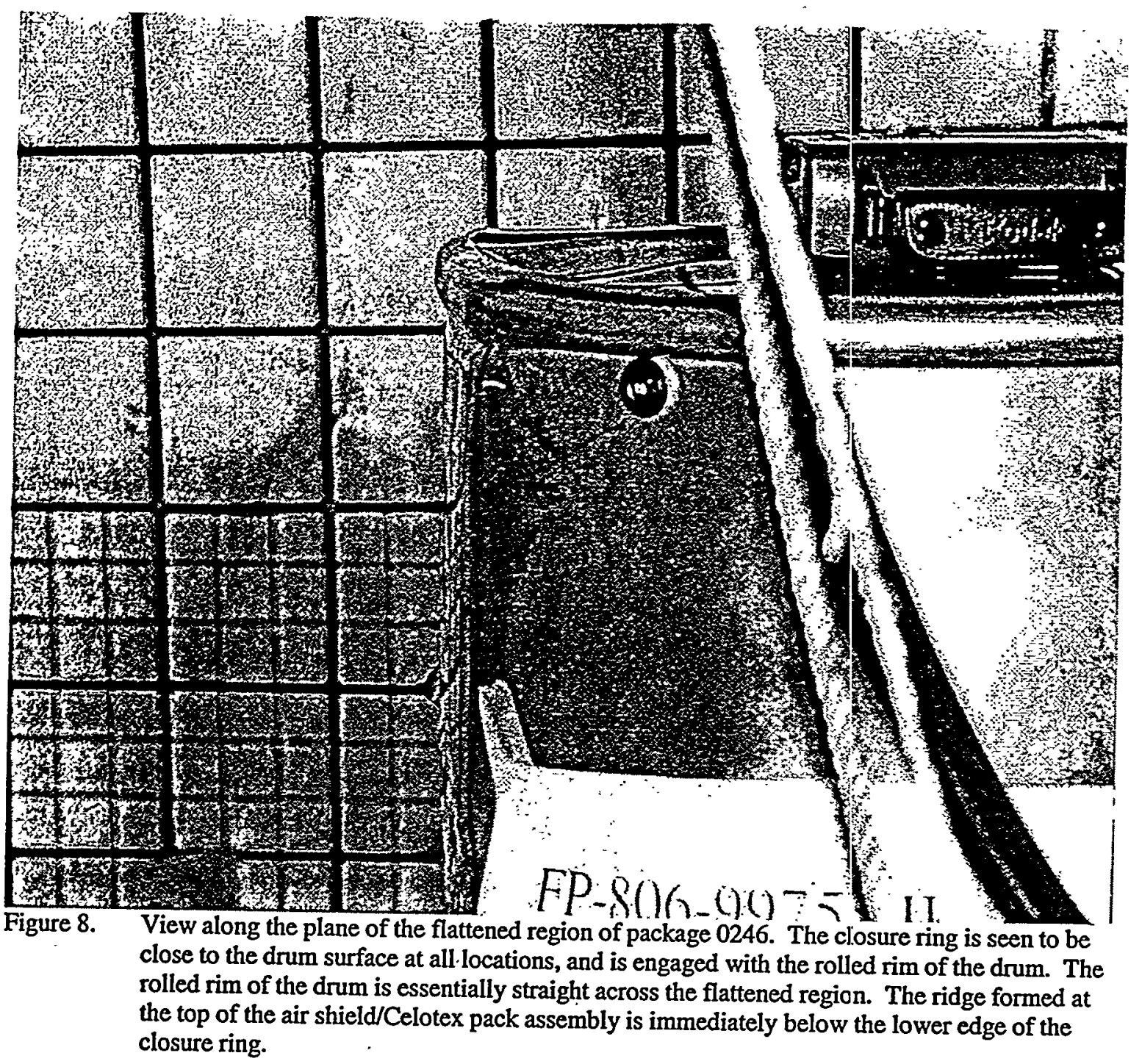




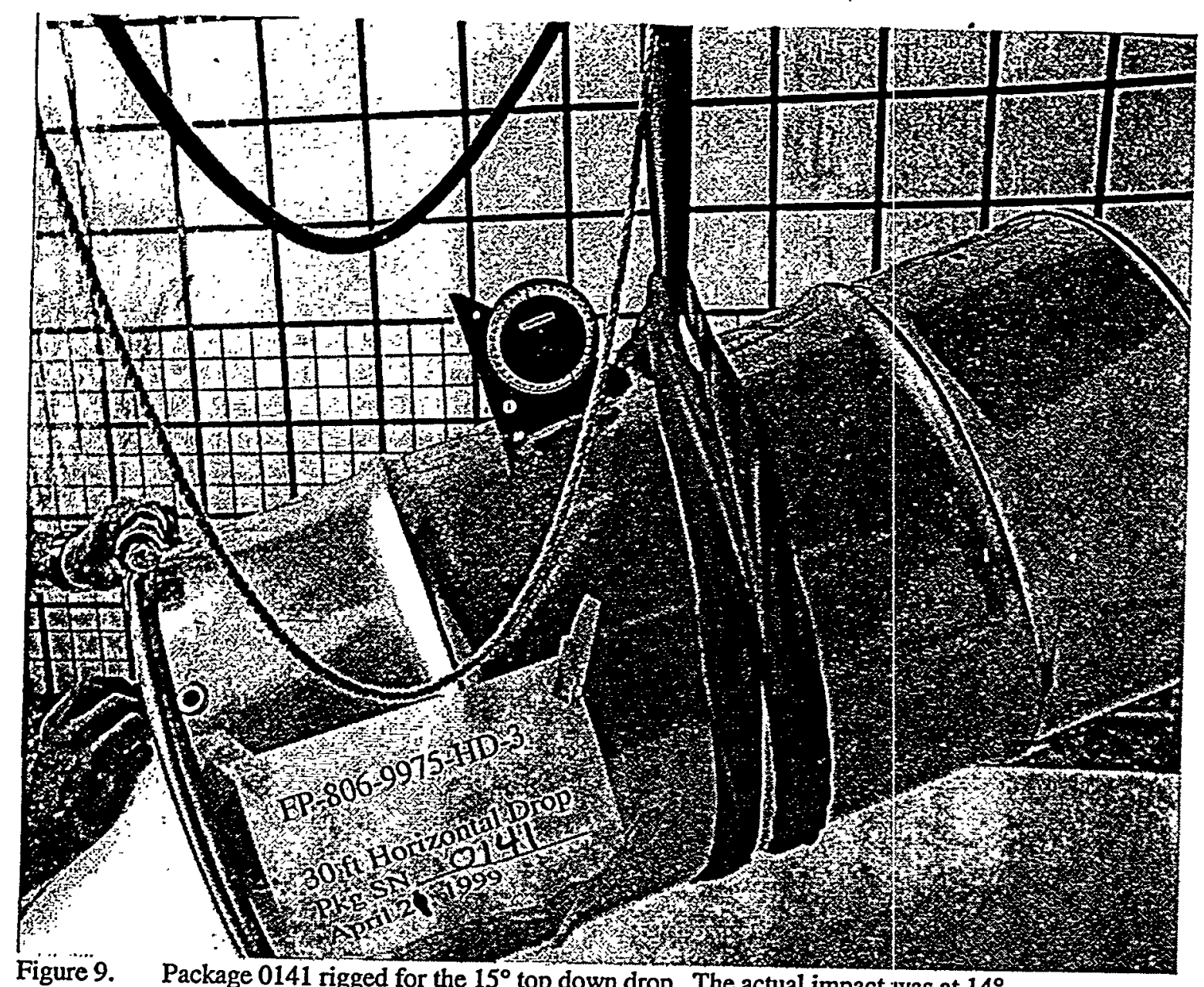

Figure 9. Package 0141 rigged for the $15^{\circ}$ top down drop. The actual impact was at $14^{\circ}$. 


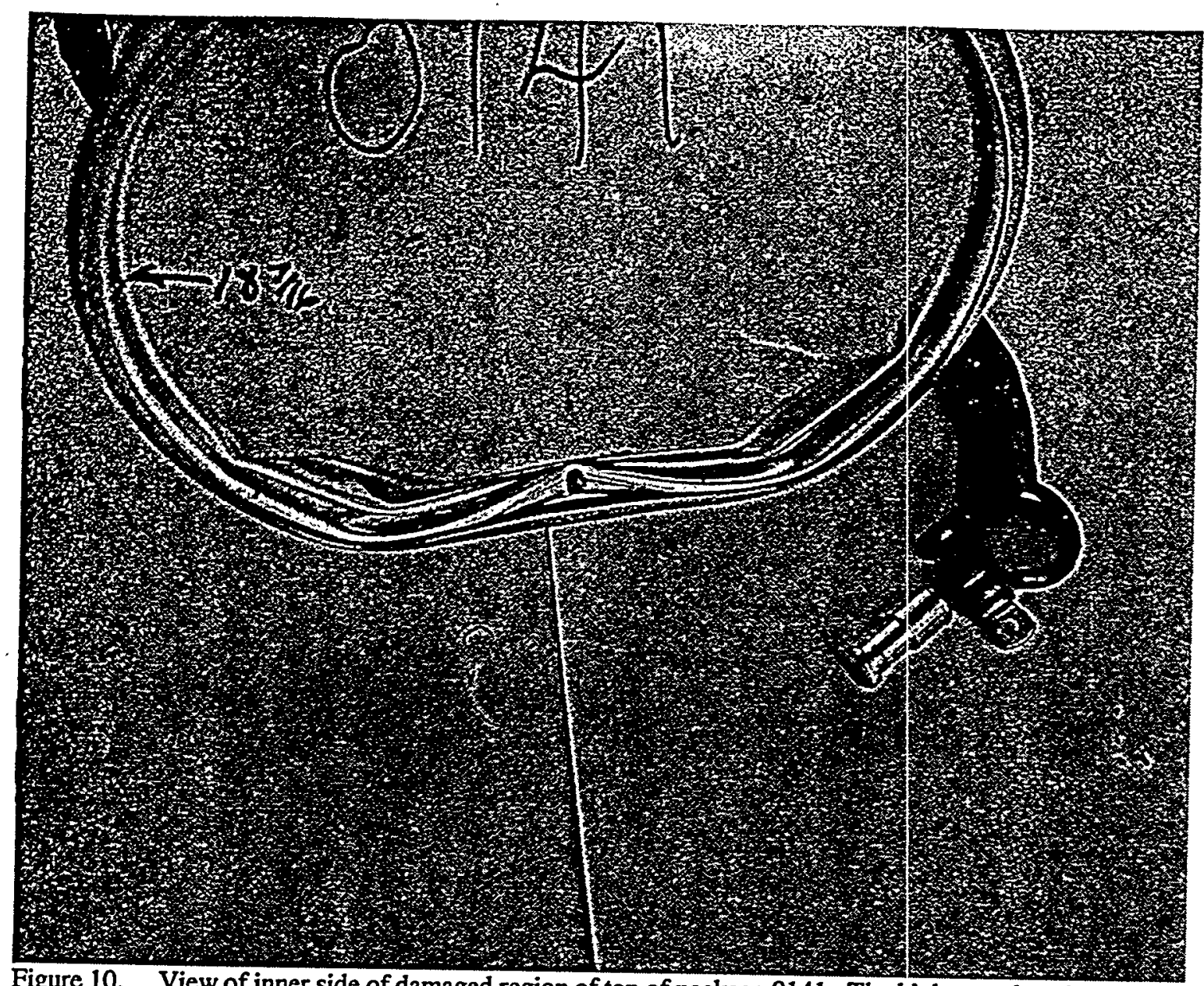

Figure 10. View of inner side of damaged region of top of package 0141. The hugher angle at impact resulted in more damage in the region of initial impact. More extensive buckling of the top is
apparent in this view. 


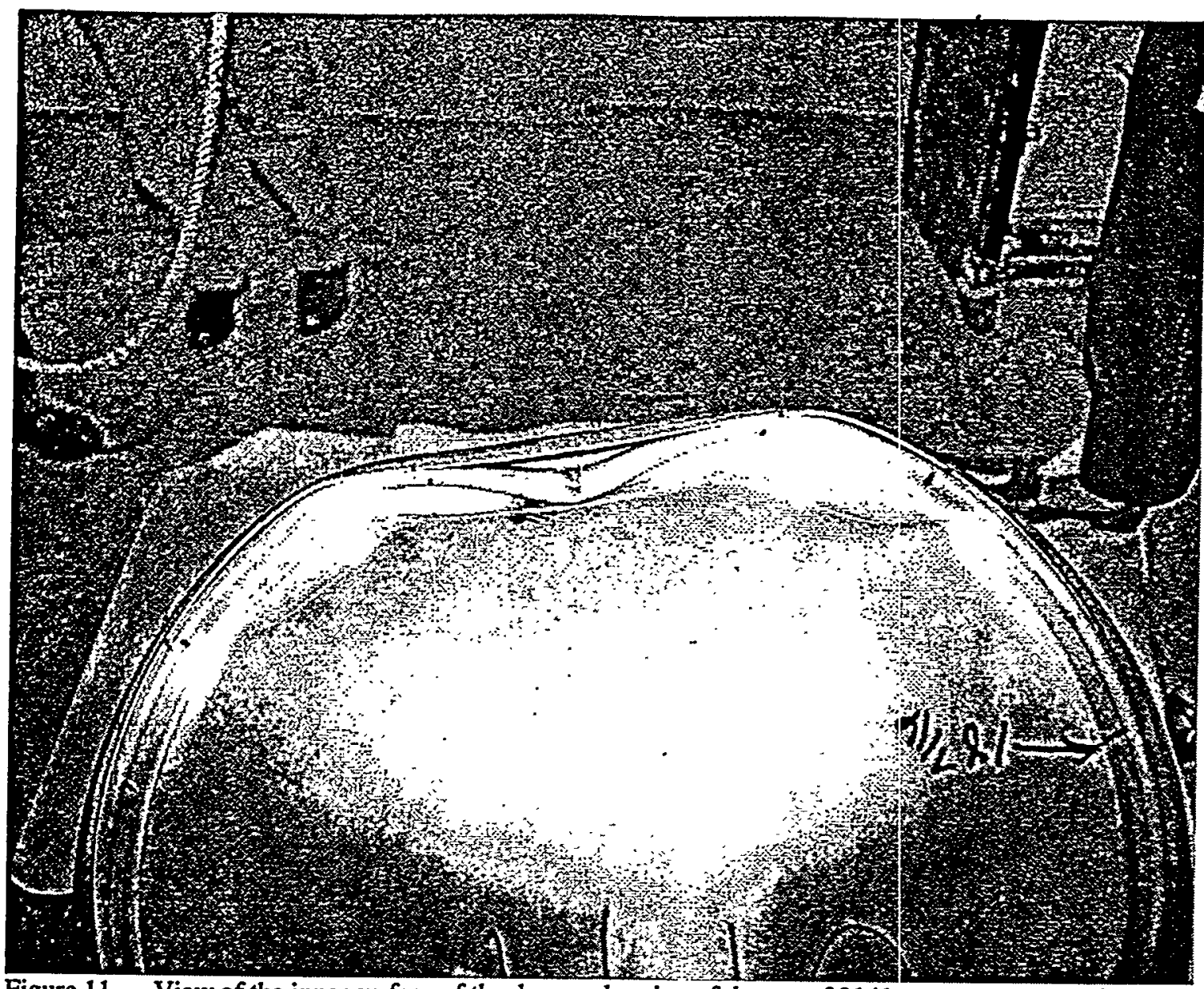

Figure 11. View of the inner surface of the damaged region of the top of 0141 


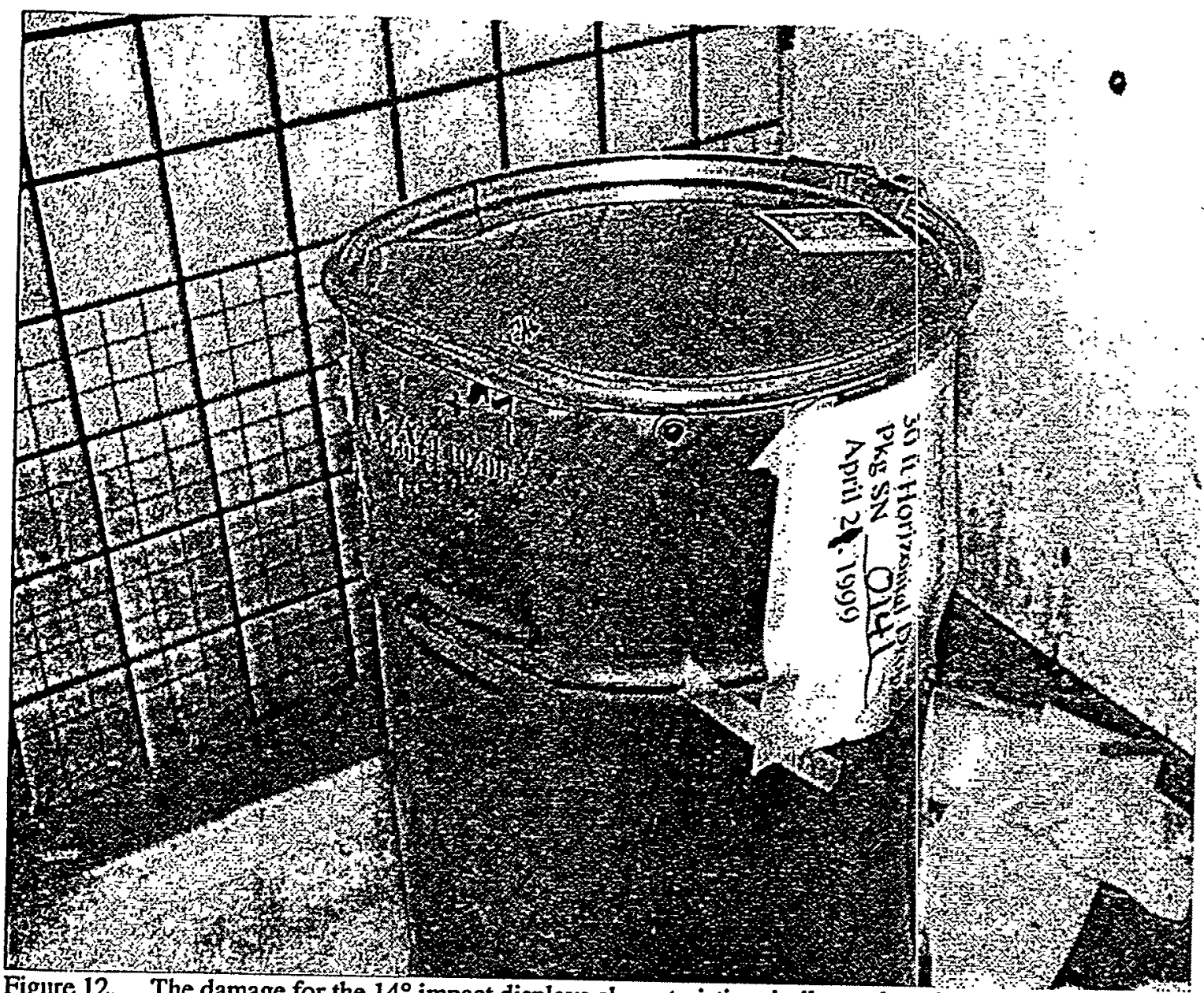

Figure 12. The damage for the $14^{\circ}$ impact displays characteristics similar to that observed in higher angle corner drops. The most significant damage is confined to the trapezoidal flattened region. Buckling of the transition regions between the curved sides and the flattened area is more pronounced and there is more extensive buckling of the top than in the lower angle
impact cases. 


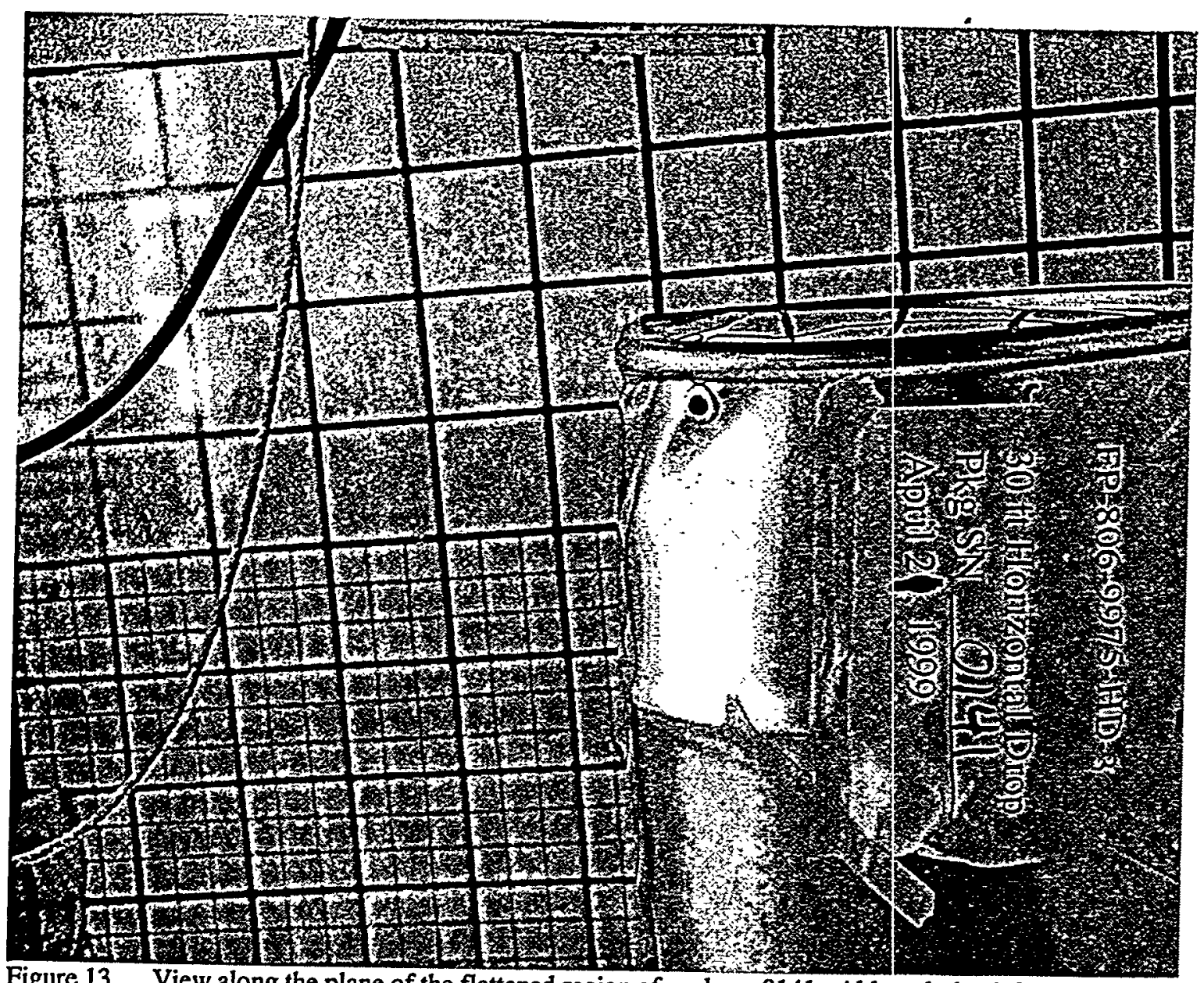

Figure 13. View along the plane of the flattened region of package 0141. Although the deformation is greater than in the previous cases, the closure ring is seen to be close to the drum surface at all locations, and is engaged with the rolled rim of the drum. The ridge formed at the top of the air shield/Celotex pack assembly is immediately below the lower edge of the closure ring. The closure ring " $C$ " section is flattened at the transition between the damage region and the curved, undamaged region. 


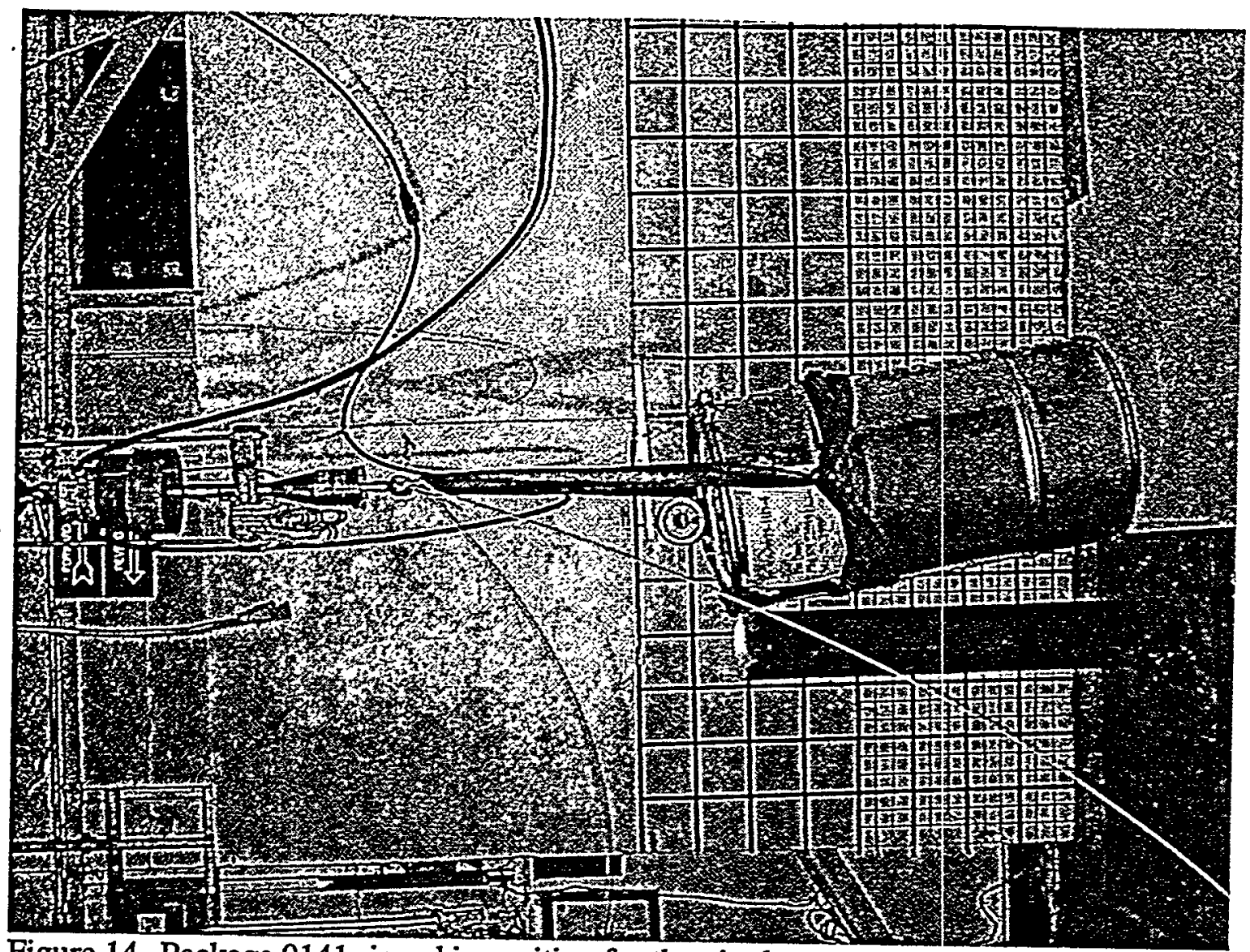

Figure 14. Package 0141 rigged in position for the pin drop test. The target was the closure ring at the transition from the flattened region to the curved, undamaged region. 


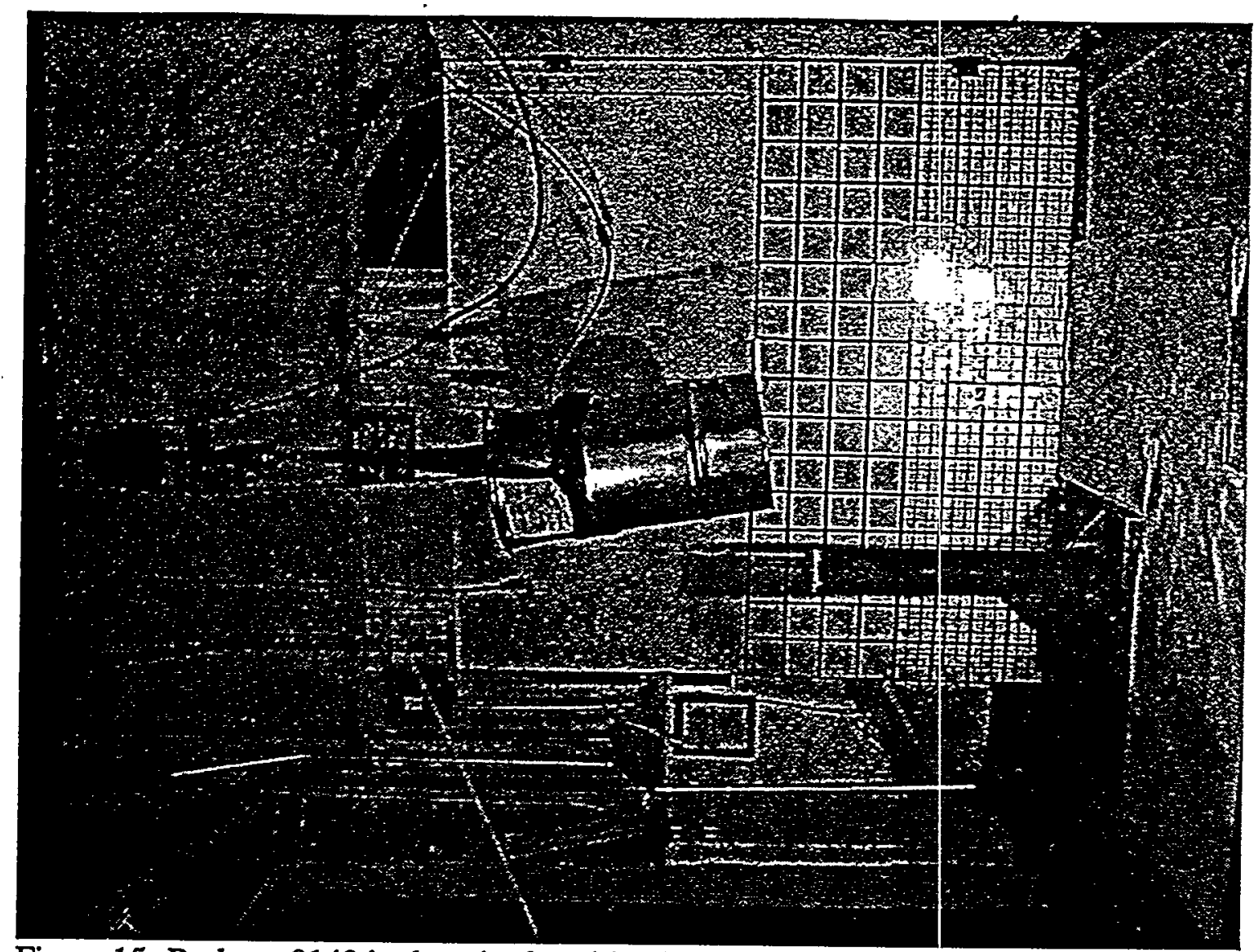

Figure 15. Package 0142 in the raised position in preparation for the pin drop test. The plumb bob confirms the target alignment. 


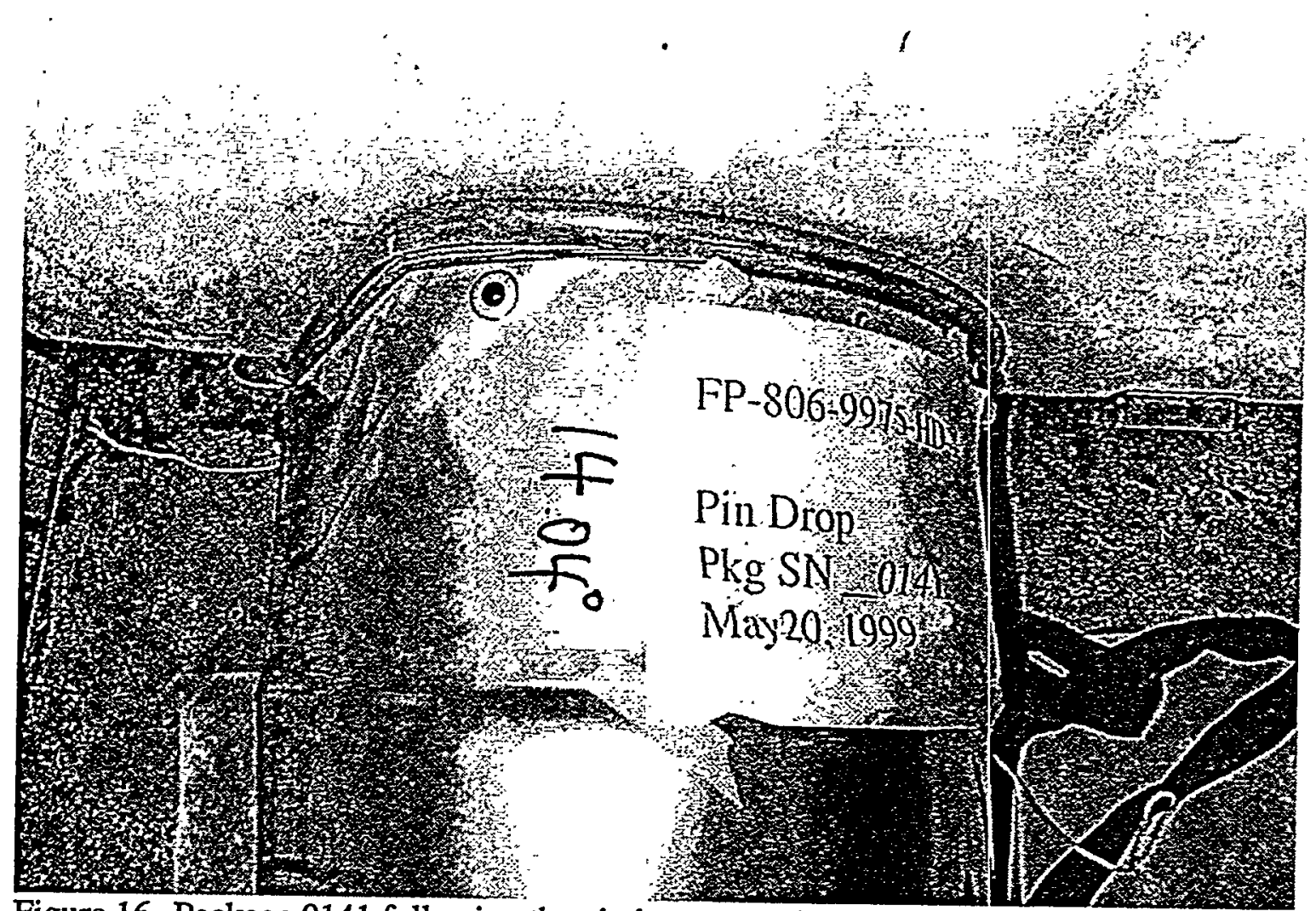

Figure 16. Package 0141 following the pin impact on the bottom of the closure ring. The impact is seen to have forced the ring over the rolled rim of the drum. 


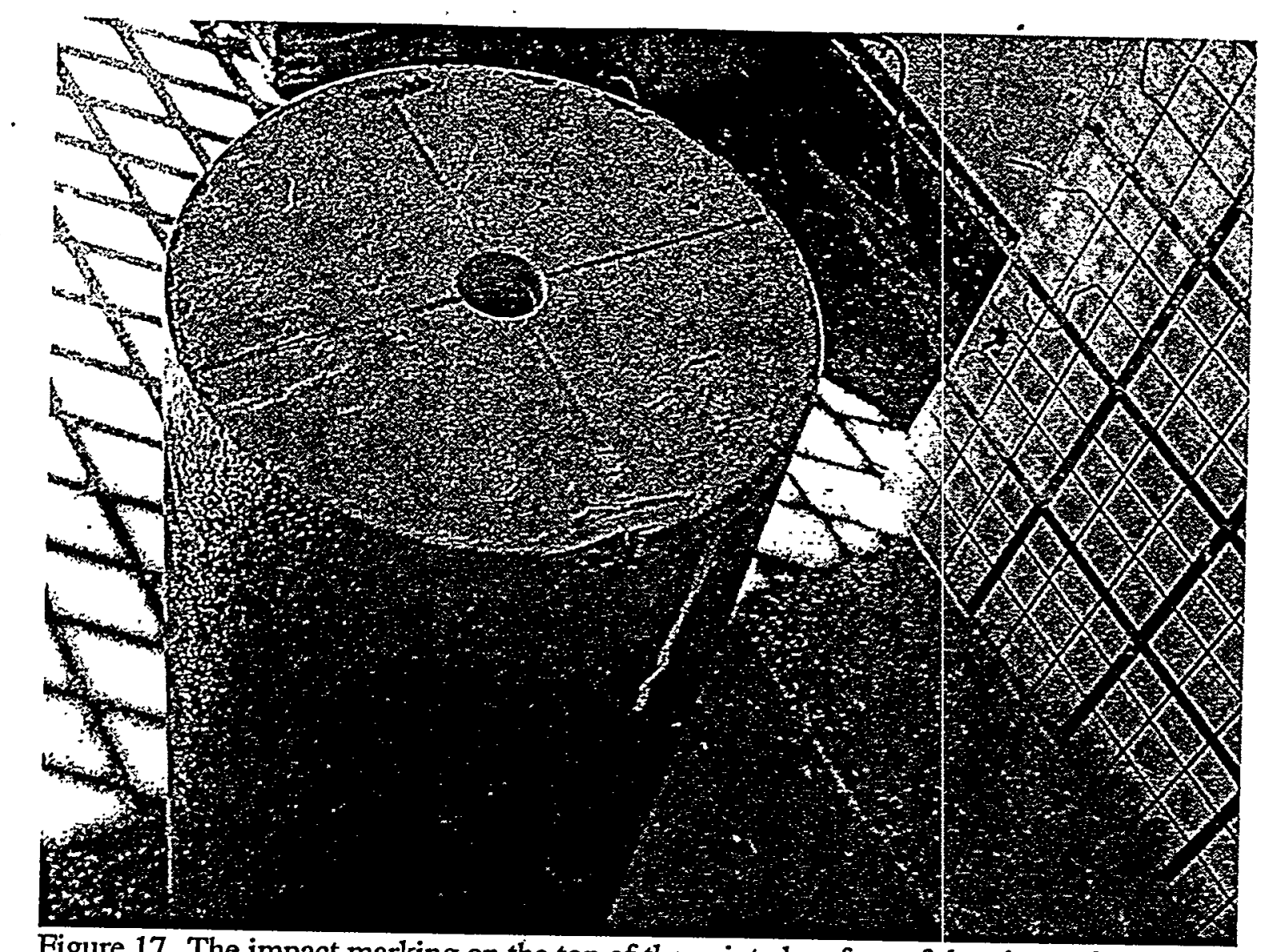

Figure 17. The impact marking on the top of the painted surface of the pin confirms that the closure ring struck the pin squarely. 


\section{WSRC-TR- $99-00327$}

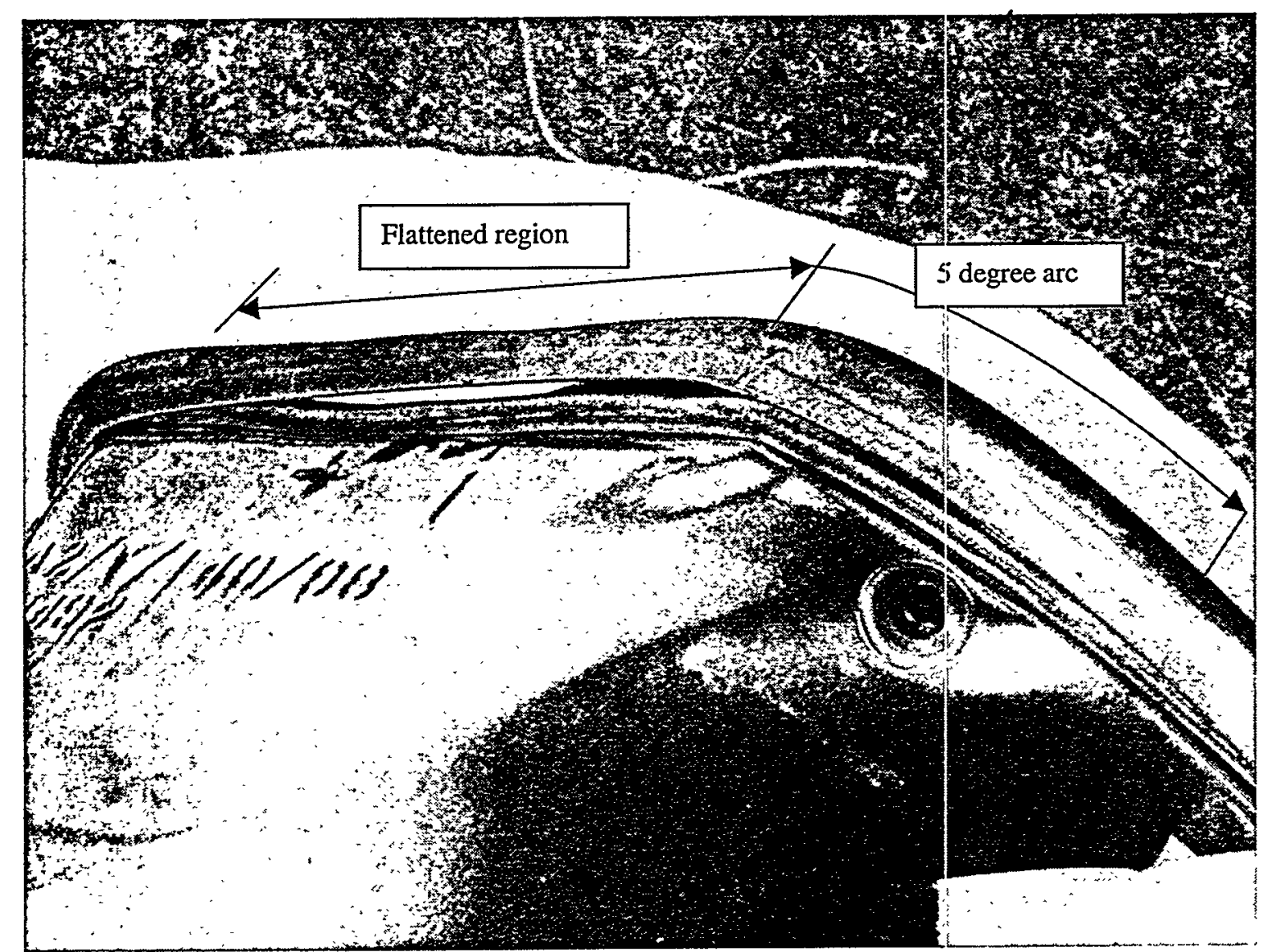

Figure 18. Close-up view of the target area. The view shows that the closure ring struck the pin at its most vulnerable location, at the point of transition between the flattened side and the curved, undamaged region. The ring was pushed just over the rolled rim of the drum. The rolled rim of the drum, visible here, is seen to be almost straight in the flattened region, not following the reverse curvature shown by the edge of the top in the top views. 


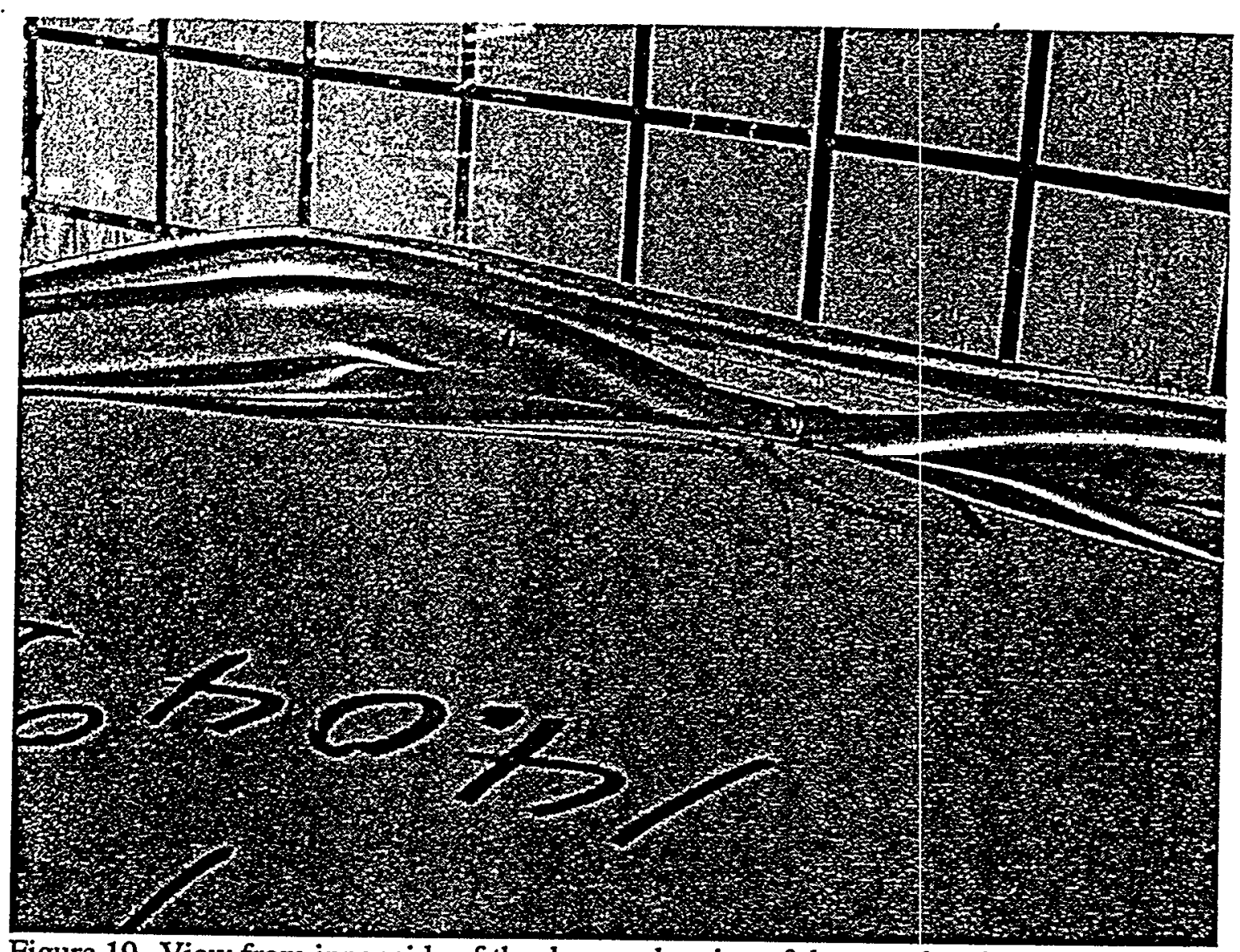

Figure 19. View from inner side of the damaged region of the top, showing the buckling of the edge and disk of the top and the inner surface of the closure ring in its. displaced position. 


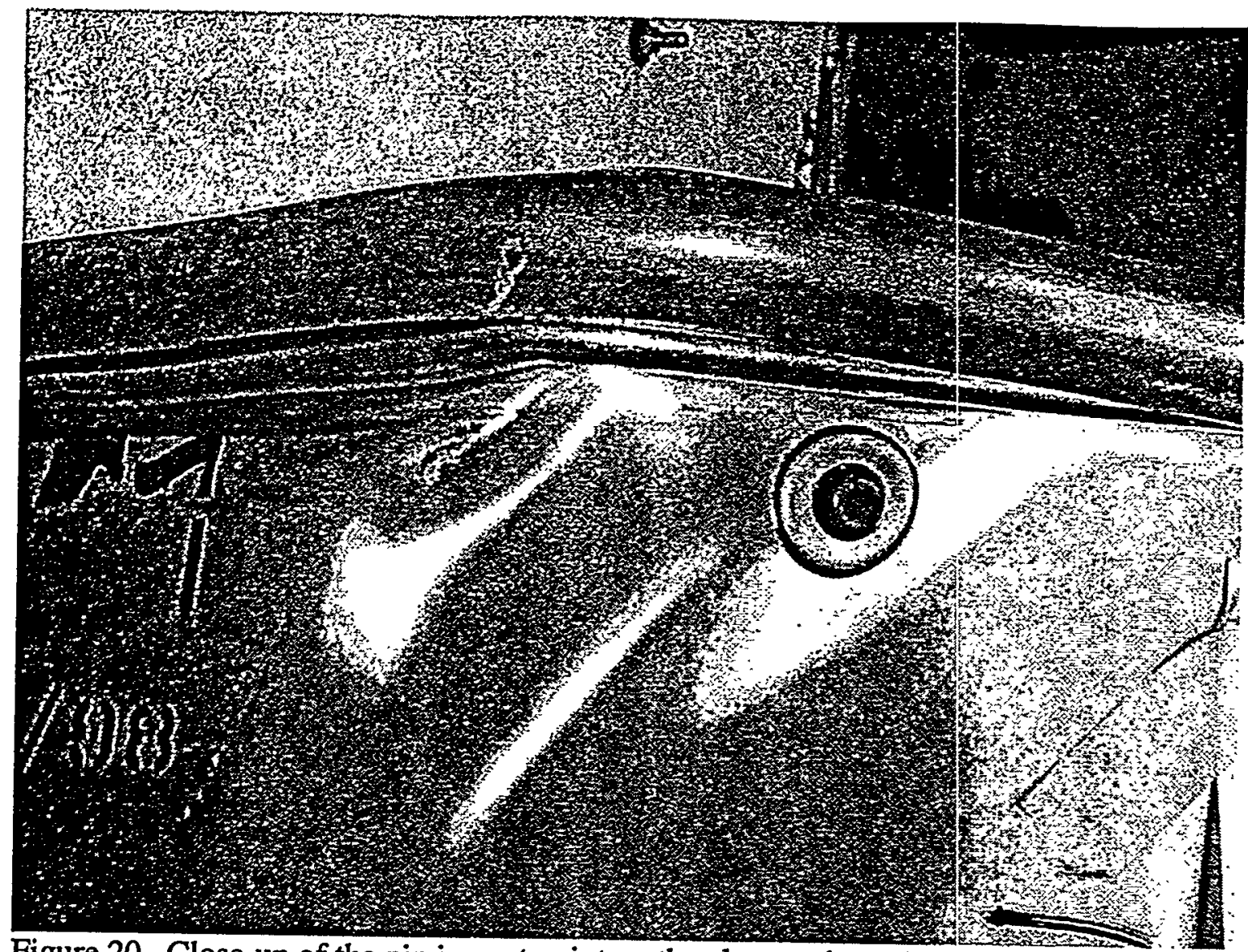

Figure 20. Close-up of the pin impact point on the closure ring. As indicated by the mark on the ring, the pin struck the bottom edge of the ring at the transition between the flattened side and the undamaged curved region. The flattened section of the rolled rim of the drum is clearly show in this view. The parallel ridge marking the top of the air shield-Celotex pack assembly is seen close to the rolled rim. 


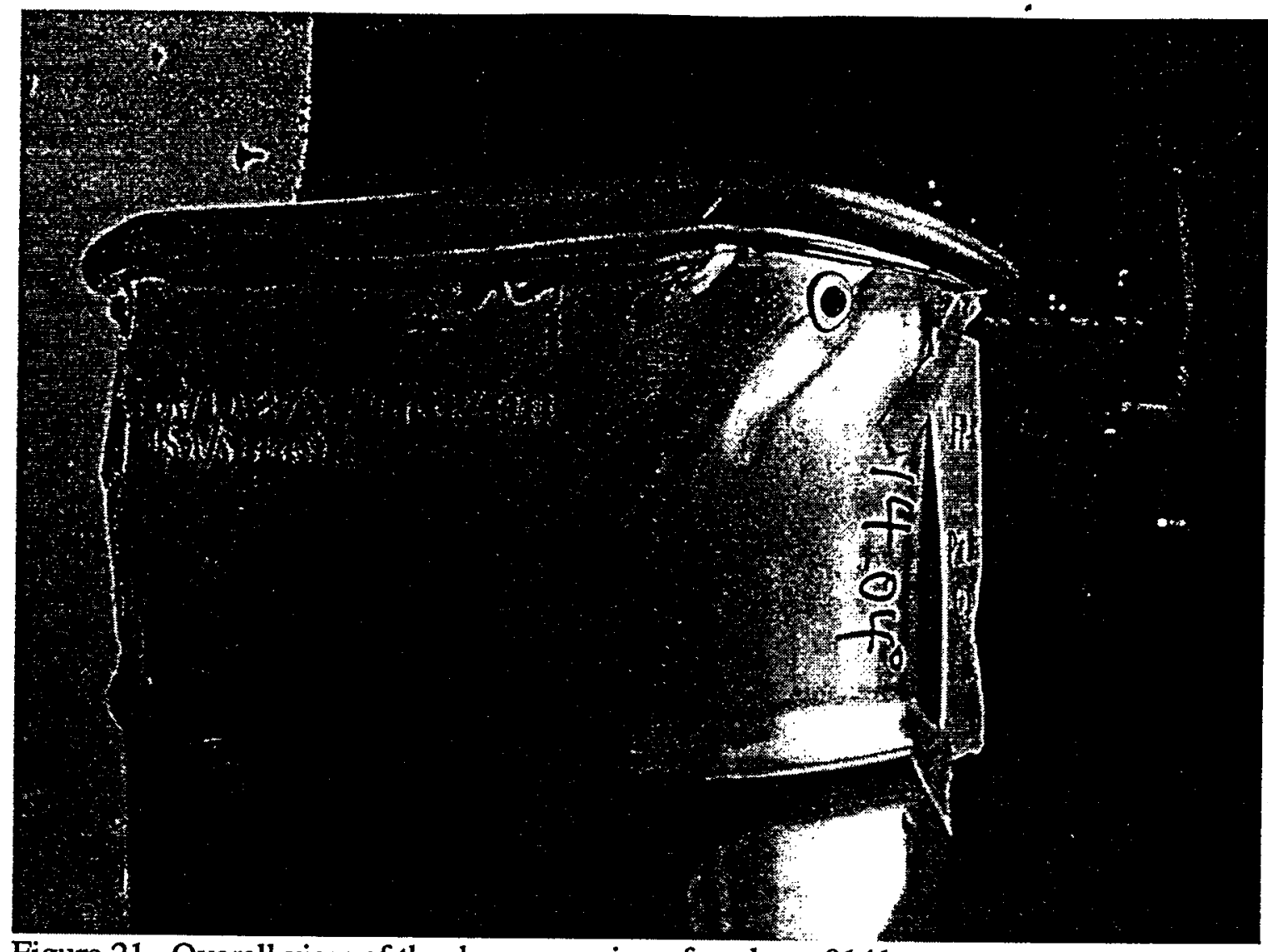

Figure 21. Overall view of the damage region of package 0141 . 


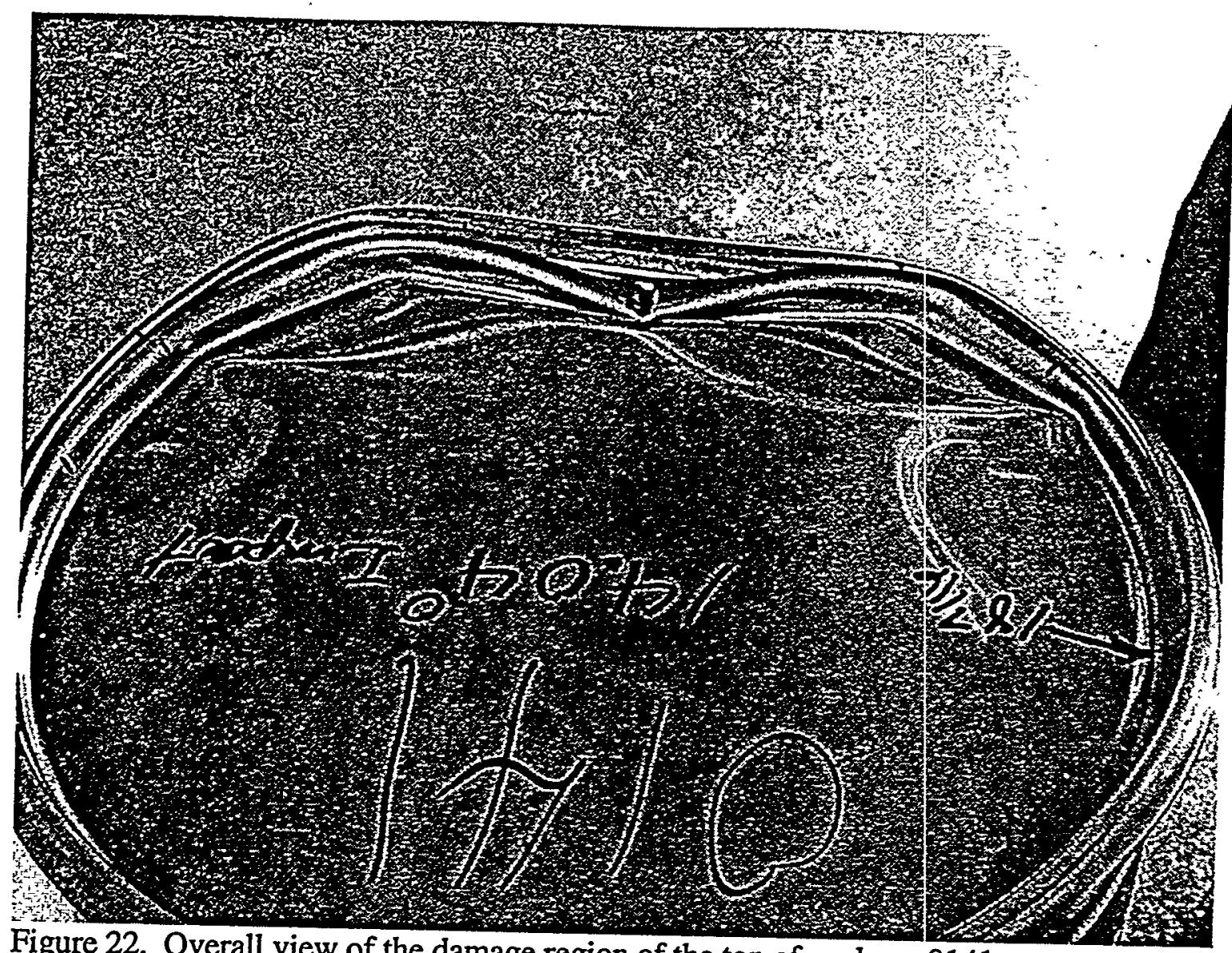

Figure 22. Overall view of the damage region of the top of package 0141 . 